\title{
Can the Distributional Impacts of Macroeconomic Shocks Be Predicted?

\author{
A Comparison of the Performance of Macro-Micro Models \\ with Historical Data for Brazil
}

\author{
Francisco H. G. Ferreira (World Bank), Phillippe G. Leite (World Bank) \\ Luiz A. Pereira da Silva (World Bank) and Paulo Picchetti (USP-FIPE) ${ }^{1}$ \\ Fferreira@worldbank.org, Pleite@worldbank.org \\ Lpereiradasilva@worldbank.org, Picchetti@fipe.com
}

\begin{abstract}
:
What was the impact of Brazil's 1998-99 currency crisis - which resulted in a change of exchange rate regime and a large real devaluation - on the occupational structure of the labor force and the distribution of incomes? Would it have been possible to predict such effects ahead of the crisis? This paper presents an integrated macro-micro model of the Brazilian economy in 1998. The model consists of an applied general equilibrium macro-econometric component, connected through a set of linkage aggregate variables to a microeconomic model of household incomes. We use this framework to predict the employment and distributional consequences of the 1999 Brazilian currency crisis, based on 1998 household survey data. We then test the predictive performance of the model, by comparing its simulated results with the actual household survey data observed in 1999. In addition to the fully integrated macromicro model, we also test the performances of the micro-econometric model on its own, and of a "representative household groups" approach. We find that the integrated macro-micro econometric model, while still inaccurate on many dimensions, can actually predict the broad pattern of the incidence of changes in household incomes across the distribution reasonably well, and much better than the alternative approaches. We conclude that further experimentation with these tools might be of considerable potential usefulness to policymakers.
\end{abstract}

Key Words: Crises, Poverty, Inequality

JEL: D31, D58

World Bank Policy Research Working Paper 3303, May 2004

The Policy Research Working Paper Series disseminates the findings of work in progress to encourage the exchange of ideas about development issues. An objective of the series is to get the findings out quickly, even if the presentations are less than fully polished. The papers carry the names of the authors and should be cited accordingly. The findings, interpretations, and conclusions expressed in this paper are entirely those of the authors. They do not necessarily represent the view of the World Bank, its Executive Directors, or the countries they represent. Policy Research Working Papers are available online at http://econ.worldbank.org.

\footnotetext{
${ }^{1}$ Picchetti is with FIPE and the Department of Economics, FEA / USP. Ferreira, Leite and Pereira da Silva are with the World Bank. We are grateful, without implication, to François Bourguignon and Anne-Sophie Robilliard for their guidance and inspiration. We are also thankful to Armando Castelar Pinheiro, Aart Kraay and Alexandre Samy de Castro for useful comments on a previous version.
} 


\section{Introduction}

Currency and financial crises - such as those seen in Mexico in 1996, in various countries in East-Asia between 1997 and 1999, in Russia in 1998 and in Brazil in 1999 - can have devastating impacts on government budgets and on private sector balance sheets alike. But that is not all: there is increasing awareness that such macroeconomic shocks do not affect all households identically. Occupational structures across the labor market respond to changed relative prices and to new expenditure aggregates. So do the distributions of earnings generated in those labor markets, and thus the distributions of household income per capita. Evidently, summary measures of poverty and inequality are therefore also affected.

There is now an established typology of the common elements preceding and causing financial crises in emerging markets. ${ }^{2}$ There is also a growing literature documenting the impact of different crises and shocks on poverty and inequality. ${ }^{3}$ Such detailed analysis of the actual, ex-post distributional impacts of specific macroeconomic events is extremely valuable and, in some sense, is the inevitable first step. But it does not provide much guidance to policymakers facing the likelihood of similar shocks in other economies, with different sectoral make-ups and institutions. Such a hypothetical policy-maker might like to compare the likely distributional impacts of two alternative stabilization strategies, such as a tighter monetary policy vis-à-vis a tighter fiscal policy. She might like to know whether the negative impact of a devaluation on the balance sheets of (predominantly urban) firms indebted in hard currencies might be offset by income gains in the rural tradable sector. In designing safety-nets to cope with the crisis, she might wonder which sectors would be most hurt by declines in the demand for labor, and whether they are likely to respond predominantly through lower wages, or through higher unemployment.

Much less progress has been made on understanding the actual transmission mechanisms through which aggregate shocks affect individual incomes and occupations across the economy, in a way that would help such a hypothetical policymaker. Given its general equilibrium nature, this problem has traditionally been approached through computable general equilibrium models (CGEs), where all individuals and

\footnotetext{
${ }^{2}$ Most if not all financial crisis in emerging markets (a) occurred after significant financial liberalization under rigid exchange rate regimes; (b) were preceded by massive capital inflows that allowed the accumulation of significant unhedged foreign currency liabilities by domestic agents that became illiquid or insolvent when these capital flows suddenly reversed; and (c) tended to cause contagion and spread to other countries. The literature has also proposed interpretations of the origin and spread of the crises ranging from a "fundamentalist" view (i.e. the crises resulted from weak macroeconomic and financial fundamentals) to a "financial panic" view (i.e. the crises were selffulfilling due to investors' behavior unrelated to economic conditions. For a survey, see Pereira da Silva (2001).

${ }^{3}$ See, for instance, Lokshin and Ravallion (2000) on the case of Russia, and Kakwani (1998) on Thailand. Baldacci, Mello and Inchauste (2002) use cross-country analysis to show that financial crises tend to have a negative impact on the income distribution and to increase poverty. There is also comparative work on the impact of financial crises in Asia and Latin America on labor markets and household incomes, such as Fallon and Lucas (2002). They conclude that employment fell by much less than production in crisis-hit countries, but that there were considerable changes in employment status, location and sectoral composition. They also show that cuts in real wages (due to real depreciation of the currency) were accompanied by small rises in unemployment and that families smoothed their incomes through increased participation and private transfers.
} 
households in an economy are lumped together into a much smaller number of representative household groups (RHGs). See, e.g. Adelman and Robinson (1988). While the literature applying CGEs to developing countries has generated a number of useful insights, its use for addressing distributional questions has been particularly problematic. In addition to the usual problems of lack of transparency and robustness (see Stern, 1989), CGE models have suffered from the fact that changes in individual occupations and earnings can be very heterogeneous even within the sectors of economic activity and skill levels traditionally used to construct RHGs. Bourguignon, Robilliard and Robinson (2002) show, for the case of Indonesia in 1998-1999, that poverty and distributional effects simulated using RHGs can be very different from those effects simulated on disaggregated real households.

In this paper, we explore a promising new approach: combining a macroeconomic model based on a set of "extended IS-LM" equations, estimated econometrically on time-series data, with a simple microeconomic model of household income formation, estimated on cross-section data from a household survey. Although the approach is similar to the one proposed by Bourguignon, Robilliard and Robinson (2002), we do not calibrate the macroeconomic model with ad-hoc parameters. Instead, we obtain as many of them as possible from macro-econometric models estimated on time-series national accounts and aggregated household survey data from Brazil, 1981-2000. Second, we compare our counterfactual results for 1999 with the actual changes revealed by the 1999 household survey data, thus providing the first actual test of the performance of an integrated macro-microeconomic model against real data that we are aware of.

In fact, the paper compares three types of model predictions with the actual observed impact. Our model operates on two levels: the applied general equilibrium model of the economy on "top" and the reducedform household income determination model at the "bottom". Linking the two are some key linkage aggregated variables (LAVs), which represent the price, wage and employment vectors generated by the macro-model. The modeling framework is described in Figure 1. We use this framework to construct three types of experiments to assess the predictive performance of each of them. The first experiment is designed to define the counterfactual income distribution that would arise from a "representative household group" approach. In order to separate errors from the RHG assumption from those arising from the macro model, we actually use the empirically observed - rather than the predicted - LAVs. Average values (for each RHG) of the empirical changes are then imputed to individual households in the 1998 dataset. In the second experiment, the same observed LAVs are used, but now the disaggregated micro model is used to impute changes to individual households. In the third experiment we combine the results of simulations using the macro model with simulations using the micro model. In a nutshell, the three experiments can be summarized as in Figure 2. 
Figure 1: A simplified overview of the macro-micro framework

“Top" Level : Macro

\begin{tabular}{l}
$\begin{array}{c}\text { General Equilibrium Macroeconomic Model } \\
\text { With Sectoral Disaggregation to model } \\
\text { Factor Markets }\end{array}$ \\
Linkage Aggregate Variables (LAVs) \\
" Level : Micro \\
\hline Household occupational choice model \\
\hline Household income determination model \\
\hline
\end{tabular}

Figure 2: An overview of the three experiments conducted

\begin{tabular}{|c|c|c|c|c|}
\hline & & Top Level Macro Model & $\begin{array}{l}\text { Linkage Aggregate } \\
\text { Variables (LAVs) }\end{array}$ & Botom Level Micro Model \\
\hline Experiment 1: & $\begin{array}{c}\text { Representative } \\
\text { Household Group } \\
\text { (RHG) }\end{array}$ & No macro-simulation & $\begin{array}{l}\text { LAVs : actual observed } \\
\text { changes of average } \\
\text { income and employment } \\
\text { for each RHG }\end{array}$ & $\begin{array}{l}\text { No micro-simulation: Each } \\
\text { individual receives the } \\
\text { average income and } \\
\text { employment change of the } \\
\text { RHG he/she belongs to }\end{array}$ \\
\hline Experiment 2: & $\begin{array}{l}\text { Pure Micro } \\
\text { Simulation using } \\
\text { the Household } \\
\text { Income Micro- } \\
\text { Simulation model }\end{array}$ & $\begin{array}{c}\text { No macro-simulation or } \\
\text { "perfect disaggregated } \\
\text { macro model" using } \\
\text { actual observed average } \\
\text { income and employment } \\
\text { change of the economy's } \\
\text { RHGs }\end{array}$ & $\underline{\text { No LAVs }}$ & $\begin{array}{l}\text { Pure micro-simulation: micro } \\
\text { model runs so that its } \\
\text { average results for each RHG } \\
\text { converge to the actual } \\
\text { observed average income } \\
\text { and employment change of } \\
\text { the economy's RHGs }\end{array}$ \\
\hline Experiment 3: & $\begin{array}{l}\text { Full Macro-Micro } \\
\text { Linkage model }\end{array}$ & $\begin{array}{l}\text { Macro simulation: macro } \\
\text { model runs to replicate } \\
\text { the } 1999 \text { financial crisis }\end{array}$ & $\begin{array}{c}\text { LAVs : simulated } \\
\text { changes of average } \\
\text { income and employment } \\
\text { for each RHG }\end{array}$ & $\begin{array}{c}\text { Micro-simulation: micro model } \\
\text { runs so that its average } \\
\text { results for each RHG } \\
\text { converge to the simulated } \\
\text { average income and } \\
\text { employment change of the } \\
\text { model's RHGs }\end{array}$ \\
\hline
\end{tabular}


This exercise is fraught with an array of perils and pitfalls. Perhaps most importantly, the parameters in reduced-form macroeconomic models usually conflate "deep" taste and technology parameters with policy parameters, and are thus subject to the Lucas critique that estimates obtained under a certain policy regime may no longer be valid under another. But there are other issues: national accounts data used for estimating the macro model may be at odds with the aggregated picture arising from the household survey data used to estimate the micro model. Assumptions about labor market closures are inevitably oversimplifications of a much more complex reality, likely to involve a search-driven equilibrium unemployment rate. And so on.

We pursue this approach, despite these serious data and methodological limitations, because of the sheer importance of the question. The ability to predict, with some amount of confidence, the direction and magnitude of the impacts of large macroeconomic events on the incomes and occupations of individuals across the income distribution would be a major asset to policy-making in a number of countries, particularly those that combine the unfortunate characteristics of being both volatile - or shockprone - and poor. While we do not believe that this paper fully achieves that objective, we hope that the comparisons of our model predictions with the real data, and our decomposition of the errors into elements due to each of the macro and micro components, may be useful to other applied researchers working on this important question.

The paper is organized as follows. Section 2 briefly describes the event that we are seeking to model: the 1998-99 currency crisis with the floating and devaluation of the Real, and the structure of the macroeconomic model used for Brazil. The procedure to generate LAVs, and the precise scenario of the currency crisis that is simulated are presented in Section 3. Section 4 describes the microeconomic model of income determination at the household level, and the results of the micro-simulation based on them. The micro model accuracy and the simulations are presented in Section 5. Section 6 concludes.

\section{The 1998-1999 Currency Crisis and the Macroeconomic Model}

The macro model that will be outlined in this section was designed to simulate the historical scenario corresponding to the policy package implemented during 1998-1999 in Brazil. This package consisted chiefly of the abandonment of Brazil's crawling-peg exchange rate regime. During most of the first four years of the Real Plan (July 1994-January 1999), Brazil maintained a crawling-peg exchange rate regime (ERR). The crisis started around the third and fourth quarter of 1998 with pressure on the exchange rate coming from capital outflows. The pressure continued during the first quarter of 1999 after the depegging of the Real. The policy response comprised -among other less salient policies-changes in the following variables: 
- The "float" of the currency on January 15, 1999 whose average annual parity with the USD goes up from $\mathrm{R} \$ 1.161$ (annual 1998 average) to one USD to $\mathrm{R} \$ 1.816$ (annual 1999 average corresponding to a $56.4 \%$ devaluation).

- A temporary rise the central bank policy rate (BACEN's Selic) during the period corresponding to October 1998 until May 1999. The monthly rate was raised from 1.47\% in August 1998 up to $3.33 \%$ in March 1999 (corresponding to annualized rates of almost 50\%). However, thanks to the rapid resolution of the crisis, the annual average base nominal rate in 1999 ended up actually lower than in 1998. In nominal terms, the Selic was set in 1997, 1998 and 1999 respectively at $24.8 \%, 28.8 \%$ and $25.6 \%$, corresponding to real average rates respectively of $16.1 \%, 26.6 \%$ and $4.7 \%$.

- A renegotiation of the terms of the stand-by-arrangement (SBA) with the IMF in order to strengthen the credibility of the policy framework; and hence a tightening in the fiscal stance corresponding to a reduction of the consolidated public sector borrowing requirements (PSBR) from BRL68 billion to BRL56 billion (7.5\% of GDP down to $5.8 \%$ of GDP, i.e. a cut of BRL12 billion or $1.7 \%$ of GDP).

Other key aspects of the policy changes included the implementation of an inflation target anchor in 1999 as a replacement to the ER anchor; the provision of hedge to market participants (through the issuance of government "foreign-exchange-indexed" domestic bonds); and undisclosed occasional interventions on the spot market, drawing on international reserves, within the limits agreed upon under the new arrangement with the IMF.

Our goal is to model this event in the simplest possible way, consistent with the objective of generating linkage wage, price and employment variables which can be taken to the microeconomic simulation model on household data. On the household survey database, that model will allocate those average changes across households, with a view to predicting occupational and distributional impacts.

At the top of the framework, we begin with a conventional IS-LM macro-econometric general equilibrium model, but with a disaggregated labor market and a financial sector. The model is estimated on timeseries data and some equations are specified with a dynamic structure that allows for dynamics in the solution of the model. Most behavioral equations are estimated by OLS, some with an error-correction mechanism. Data availability issues imposed some constraints on the choices of estimators. ${ }^{4}$ In spite of these inevitable constraints, we estimate several equations using two-stage least squares when endogeneity of the regressors was considered to be particularly likely. The parameters of the model are

\footnotetext{
${ }^{4}$ Data on wages and employment for the disaggregated labor market could only be obtained through the household surveys, which start in the late seventies, and are available on a yearly frequency. Likewise, data for the financial sector is not available with consistent methodologies for a time span allowing a large sample.
} 
estimated on 1981-2000 annual data, both from the national accounts and from (a time-series of averages from) the Pesquisa Nacional por Amostra de Domicilios (PNAD) household surveys, which have been fielded annually by the Brazilian Census Bureau (IBGE) since $1976 .{ }^{5}$

The basic layout of the model is a disaggregated but still standard format, built around a core neoKeynesian framework (as in Klein-Goldberger, MPS in the US or DMS, Metric in France). See Artus, Deleau and Malgrange (1986). ${ }^{6}$ The functioning of these large models, albeit complex, can be reduced to the interaction of three basic modules. First, there is a real economy module, determining production, components of aggregate demand and factor demand (see below 1.2). Then, there is a wage-prices module that determines the price level and wage rates. And finally comes a financial and monetary module that determines the interest rate. Following the tradition, when prices, wages and interest rate are made endogenous, we get the standard IS-LM structure for macroeconomic models where aggregate demand and supply curves can be related to the general price level. Due to its modular structure, the macro model can function under various configurations. In the simplest case, when the goods market is completely aggregated and the financial asset market is reduced to one local currency market, we have a standard IS-LM.

The key transmission mechanism in the model between the real economy and the financial markets comes from the linkage of real private consumption and investment to the endogenous domestic interest rate, which is determined by equilibrium in the financial sector. In particular: (a) real private consumption is a standard function of disposable income, the general price index and the real deposit interest rate (to account for a "wealth" or portfolio effect); and (b) real private investment is decomposed into its building and construction versus machinery components. Both components follow a standard specification, including aggregate demand (an accelerator) and the price of capital, decomposed into the real exchange rate (given the importance of imported equipments) and the domestic working capital interest rate.

The balance of payments (BoP) is modeled in a fairly detailed way. Real services and real imports and exports of goods are disaggregated into major types of commodities and types of services. The general specification for all these items makes each of them dependent (respectively for debit and credit components) on domestic and external demand and relative prices, i.e. the real exchange rate. The current account balance is constructed by accounting identities. Capital movements follow uncovered

\footnotetext{
${ }^{5}$ PNAD data is annual except for Census years, and a few other exceptions, such as 1994.

${ }^{6}$ Macro-econometric models have usually an ad hoc treatment of expectations: e.g. naïve, adaptive mechanisms.

They are also subject to the Lucas critique: parameters in most equations are not invariant to a change in regime. The critique forced macro-models to give more emphasis on theory, long-run relationships, and the supply side, as well as specify and estimate dynamic adjustments more robustly. Models tried to incorporate rational expectations or model-consistent expectations to address the Lucas critique. The estimation strategy in our "top" macro model addresses only some of these issues. Attempts to construct macro-models based purely on a bottom-to-top aggregation of microeconomic behavior are underway (see Townsend and Ueda (2001)) but are still -for the moment-of limited practical application to evaluate the effect of macroeconomic policies.
} 
interest parity conditions and are assumed to depend only on the interest rate differential, on the expected depreciation of the exchange rate and on country risk. Historical simulations in current version of the model are based on an exogenous nominal exchange rate that is compatible with the two regimes that prevailed recently in Brazil ${ }^{7}$. Details of the model, including the exact specification of each equation in each module and the estimation results are not presented here, due to space constraints. They can be found in Pereira da Silva, Picchetti and Samy Castro (2004).

\subsection{Factor Markets in the Real Economy model}

\section{a) Aggregate Supply and Demand Modeling Strategies}

The main motivation behind the break up of supply into different sectors is the ability of the model to differentiate the effects of macro and external shocks, on different types of products - and on the workers producing them. Accordingly, the supply side in the model is divided into six sectors:

- Urban Tradable Formal (UTF)

- Urban Non-Tradable Formal (UNF)

- Urban Non-Tradable Informal (UNI)

- Rural Tradable Formal (RTF)

- Rural Non-Tradable Formal (RNF)

- Rural Non-Tradable Informal (RNI)

For each of these sectors, production is modeled as value-added, and factor demand functions are derived from factor price equals marginal product conditions.

\section{b) Factor markets}

Factor demand functions determine demand for capital and for labor by skill-level. In order to relate the employment and earnings predictions of this level of the model to the household survey data used in the micro simulation stage, the classification of workers by skill-level had to be made in terms of observed characteristics for the individuals. We chose to define skill-level according to years of formal education as reported in the PNAD. Low-skill level workers have between zero and four years of formal education, whereas intermediate-skilled workers have between five and 11 years, and high-skilled workers have more than 11 years.

\footnotetext{
${ }^{7}$ In most macro frameworks there are two possible exchange rate regimes. Under a fixed regime, the central bank intervenes in the foreign exchange market to maintain a fixed parity or a crawling peg path vis-à-vis a specific foreign currency target (say, the USD). Thus, the change in the demand for money by households is affected by this foreign component (an exogenous element in the supply of money). Under a flexible regime, the central bank does not intervene and the BoP equation determines the freely floating exchange rate. Hence, here, the exchange rate is determined in the BoP and the money market equilibrium is simply solved by the domestic component of supply and demand.
} 
The demands for these different types of labor and for capital are derived by equating factor prices to the marginal products from the production functions for each of the six sectors, which are represented by a three-level nested CES. The motivation for this approach is to provide for flexibility in the rates of substitution between capital and labor, and between the different types of labor. The first level of the CES allows for substitution between capital and a composite measure of labor. In the second level, this composite labor can be decomposed between skilled and unskilled jobs. The third level accounts for the fact that unskilled jobs can either be performed by either low-skill or intermediate-skill workers, whereas skilled jobs can either be performed by either intermediate-skill or high-skill workers. Therefore, as in Fernandes and Menezes-Filho (2001), we assume that there is substitution between all types of labor, except between high-skill and low-skill labor. The production function for each one of the six sectors can then be represented as:

$$
y=\beta\left[\lambda K^{-\rho}+(1-\lambda) L_{a}^{-\rho}\right]^{-\frac{1}{\rho}}
$$

where:

$$
\begin{aligned}
& L_{a}=\left[\delta L_{Q}^{-\psi}+(1-\delta) L_{U}^{-\psi}\right]^{-\frac{1}{\psi}} \\
& L_{Q}=\left[\phi L_{i Q}^{-\varepsilon}+(1-\phi) L_{h}^{-\varepsilon}\right]^{-\frac{1}{\varepsilon}} \\
& L_{U}=\left[\xi L_{l}^{-\gamma}+(1-\xi) L_{i U}^{-\gamma}\right]^{-\frac{1}{\gamma}}
\end{aligned}
$$

$K=$ Capital; $L_{a}=$ Composite Labor; $L_{Q}=$ Composite Labor for skilled jobs, can be performed either by $L_{i}$ (intermediate-skill workers) or by $L_{h}$ (high-skill workers); $L_{u}=$ Composite Labor for unskilled jobs, can be performed either by $L_{i}$ (intermediate-skill workers) or by $L_{l}$ (low-skill workers).

Elasticities of substitution: $\left\{\begin{aligned} \sigma_{k a} & =\frac{1}{1+\rho} \\ \sigma_{Q U} & =\frac{1}{1+\psi} \\ \sigma_{i h} & =\frac{1}{1+\varepsilon} \\ \sigma_{l i} & =\frac{1}{1+\gamma}\end{aligned}\right.$

Having defined factor demand functions based on these sectoral production functions, let us turn to factor supply functions These are separately specified by skill-level (in the case of labor) and by economic sector (for both labor and capital). Labor supply is assumed to be perfectly inelastic for each skill group, and to correspond to the economically active population (PEA) in those groups. 
Factor market equilibrium conditions are obtained by simultaneously solving equation pairs $L_{i j}^{d}(\underline{w})+U_{i}=L_{i j}^{s}$ $w_{i j}=f\left(U_{i}, \ldots\right)$

for each labor type $i$ and sector $j$. In each of these pairs, the second equation is a wage curve, which relates equilibrium wage levels to skill-specific unemployment levels. This set-up generates 48 equations for 30 unknowns: 24 endogenous factor prices and six endogenous skill-specific unemployment rates. ${ }^{8}$ We see this as a minimum requirement of a model which purports to focus on occupational and distributional consequences of shocks.

The solution to the system generates most of the linkage aggregate variables (LAVs) required for transmission to the microeconomic model. Specifically, it generates eighteen wage rates (three labor types in six sectors) and twenty-one occupation rates (six employment levels and one unemployment level for each of three types of workers). The only missing LAVs now are consumption price aggregates. In order to obtain those, however, we need to move from the factor markets to the product markets, and then to incorporate the financial markets in order to derive an endogenous set of interest rates from the IS-LM equilibrium. The first step, as we move to the product markets, is to recognize that our modeling strategy implies that the number and definition of final demand sectors are different from those of production sectors. This creates the issue of reconciling the output and price variables in the two sides of the model, which is done through a conversion matrix.

\section{c) Conversion Matrix}

Our approach follows Fisher, Klein and Shinkai (1965). On the one hand, the output demanded by the final demand sectors must be distributed over the production sectors; on the other hand, the prices generated by the price-formation equations in the production sectors must be aggregated to obtain prices for the final demand sectors. In our model, data are available on total output by formal production sector, coming from national accounts. In the case of informal sector, there is no readily available statistic on production. Therefore, value-added for these sectors was estimated based on reported incomes from informal workers in the household surveys. The output conversion matrix was estimated with the natural restrictions (e.g., non-tradable sectors do not export), and the resulting weights were then used to convert sector prices into GNP deflators.

\footnotetext{
${ }^{8}$ The 30 unknowns are four factor prices for each of six sectors (24) and six unemployment levels (one for each skill type, and separately for urban and rural areas). Capital is assumed to be fully utilized in all sectors. In practice, however, insufficient numbers of observations for highly skilled workers living in rural areas required us to group that skill type with intermediate skill workers in rural areas. Since the price of capital is not a LAV either, this reduces the number of LAVs in practice to three factor prices in five sectors (15) and five unemployment levels. To these twenty LAVs which are obtained from the solution of these systems of equations, fifteen employment levels will be added. We return to the LAVs in Section 3.
} 


\section{Figure 3: An overview of the main blocks of the macro model}

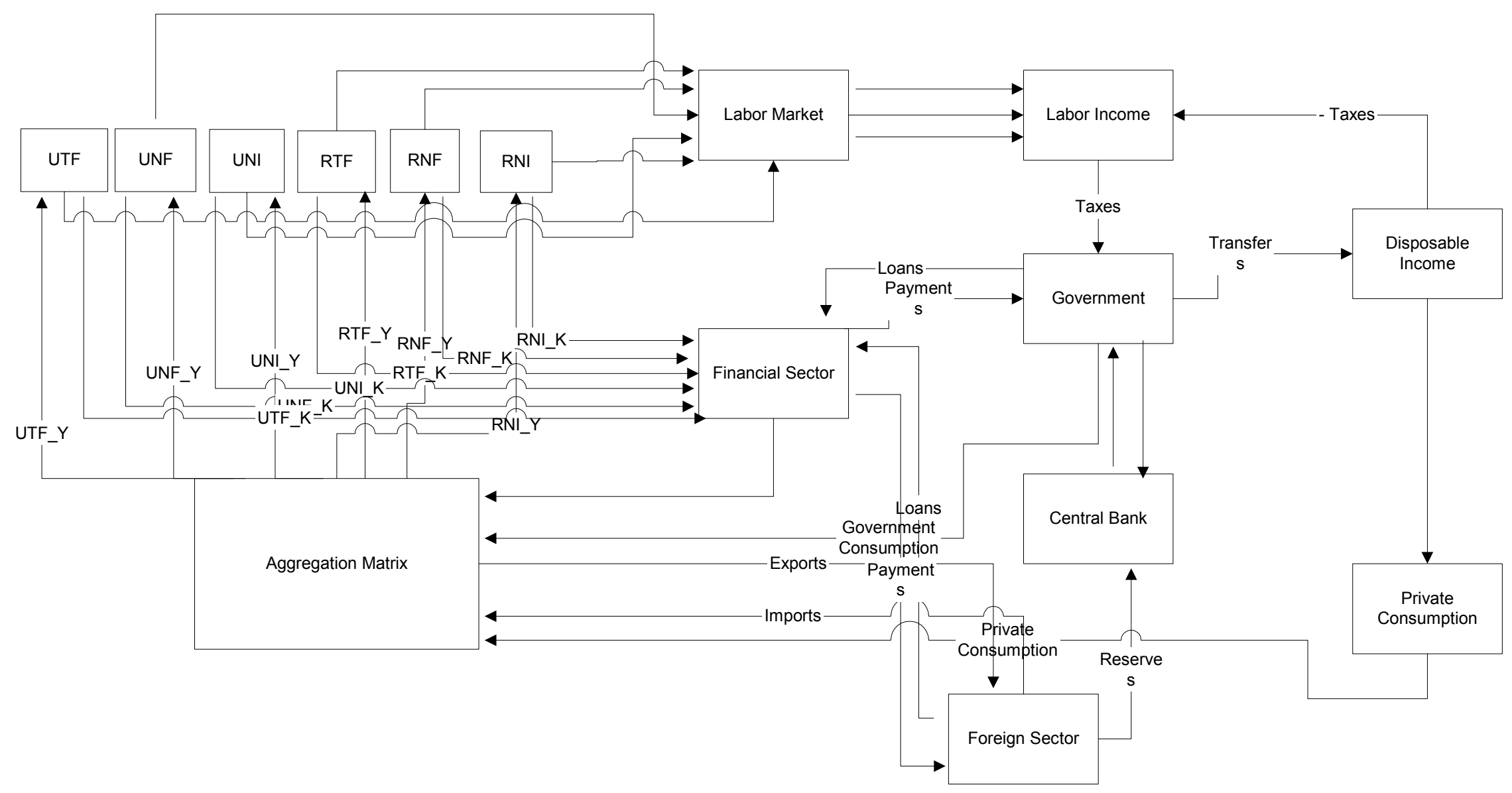




\subsection{The LM curve and the Financial sector}

Like employment levels and factor prices, product prices and interest rates are also endogenous in the macro model and related to the IS-LM framework, yielding an aggregate supply curve where production depends on the price level. In addition to the standard characteristics of the LM curve, we modeled a financial sector with several agents and markets, roughly following Bourguignon, Branson and de Melo (1989). Modeling specifically a financial sector was thought to be necessary to refine the transmission of financial crises - external and domestic - to the rest of the model, in particular to the disaggregated sectoral demand for labor and the real macro variables (real private consumption and investment) by including "portfolio choices" by agents. See Pereira da Silva, Picchetti and Castro (2004) for details.

During financial crises, many traditional policy instruments lose their ability to affect the behavior of households, firms, investors and banks, both domestic and foreign. Our exercise aims at capturing some of these episodes and their characteristics ${ }^{9}$ despite the fact that the model's simulation has an annual periodicity while most of the manifestations of these crises are infra-annual. Finally, our modeling strategy is modular, allowing the financial sector's part of the framework to be activated fully or only partially.

In particular, two domestic interest rates in local currency are endogenous in the model: the domestic deposit rate for household deposits and the domestic borrowing rate for firms (working capital interest rate). Two other interest rates are exogenous: one national (the Central Bank's policy rate, the Selic) and one foreign (a short-term Libor interest rate in US dollars). Brazil went through an abrupt change in 1999 of its exchange rate regime, from an exchange rate anchor to a floating exchange rate with inflation targeting, with a corresponding change in emphasis for the Selic. We integrated this regime change for simulations where the inflation-targeting objective prevails. Once the base policy rate is set, the structure of interest rates (domestic borrowing and deposit rates) is determined by modeling the spreads (see Favero and Giavazzi (2002), Cardoso (2002)). Spread over the base real policy rate will determine the real deposit rate given the supply of bank deposits by households and their first layer choice between local and foreign currency. Spread over the deposit rate will determine the real working capital rate given the supply of new credit by commercial banks after their first layer choice for government domestic bonds and the demand for new credit by firms. This part of the model is important to capture the short-term effect of hikes in the country's base policy rate that can result from either (a) the need under a pegged exchange rate to defend the regime by matching the rise in the country risk premium and the expected

\footnotetext{
${ }^{9}$ Shifts in agents' preferences from local to foreign currency holding, etc.; re-allocation of financial assets in the portfolio of households, firms and banks due to changes in real yields and interest rates; de-pegging and floating of the domestic currency with the pass-through effect of the depreciation feeding into domestic prices; effect of changes in the real exchange rate on exports and imports.
} 
devaluation; or (b) the need under a floating exchange rate regime with inflation targeting to establish the credibility of the anti-inflation stance of the central bank.

\subsection{Estimation and Standard Results of the Macro-econometric Model}

As mentioned above, the macro-econometric model comprises equations estimated by OLS on time series data ${ }^{10}$. The performance of the macro model (e.g., multipliers and deviations from a base casefor standard simulation exercises of fiscal and monetary shocks) is comparable to that of the macro models of developed economies (France and the US) but its investment multiplier is much weaker. These results are summarized in Table 1.

Table 1: Standard Multipliers of the Macro Model, compared to other macro models

\begin{tabular}{|c|c|c|c|c|}
\hline & $\Delta \mathrm{Y} / \Delta \mathrm{G}$ & $\Delta \mathrm{C} / \Delta \mathrm{G}$ & $\Delta \mathrm{I} / \Delta \mathrm{G}$ & $\begin{array}{c}-(\Delta \mathrm{Im} / \\
\Delta \mathrm{G})+(\Delta \mathrm{X} / \\
\Delta \mathrm{G}) \\
\end{array}$ \\
\hline PPSC Model (Brazil) & 1.31 & 0.27 & 0.29 & -0.25 \\
\hline \multicolumn{5}{|l|}{ French Models } \\
\hline DMS & 1.10 & 0.31 & 0.35 & -0.55 \\
\hline Metric & 1.38 & 0.31 & 0.66 & -0.60 \\
\hline PITI & 1.54 & 0.22 & 0.82 & -0.48 \\
\hline DECA & 1.26 & 0.37 & 0.58 & -0.69 \\
\hline \multicolumn{5}{|l|}{ US Models } \\
\hline Brookings & 2.79 & 1.11 & 0.82 & -0.14 \\
\hline $\mathrm{HC}$ & 1.74 & 0.31 & 0.53 & -0.10 \\
\hline
\end{tabular}

Source: Pereira da Silva, Picchetti and Samy de Castro (PPSC) macro model

Regarding the counterfactual simulation of the 1999 currency crisis, the macro model fares reasonably well in a historical simulation mode. Table 2 below presents partial (1995-1999) results, extracted from a dynamic historical simulation for the 1986-1999 period. The run captures the major consequences of the crisis, such as the slowdown in real private consumption, the fall in real disposable income and private investment, which explain the modest real GDP growth rate $(0.8 \%)$ in 1999 . The major components of the external sector balances are also reasonably well captured by the simulation. We should note that the Brazilian currency crisis is milder than the large output contraction that characterized other financial crises elsewhere, in the late 1990s.

\footnotetext{
${ }^{10}$ Details in Pereira da Silva, Pichetti and Samy de Castro (2004). In the present version, the simulations describe essentially movements between long-term solutions in levels. However, one of the main forthcoming extensions involves enhancement of the dynamics of the solutions by estimating movements of the variables in differences, through an error-correction mechanism. The idea, in line with the basic motivation for the proposed model, is to gain further insight into the paths of adjustment of the endogenous variables in response to shocks, allowing the analysis of trade-offs not only in terms of macro stability vs. social indicators, but also in terms of the time periods involved.
} 
The historical simulation also captures well the stabilization period under the Real Plan (mid-1994 to 1998 ) in its real and price/monetary manifestations. The major feature of the period --CPI inflation brought down from over 2,200\% per annum in 1994 to $8.5 \%$ in 1997-is portrayed by the consistent fall in inflation measured by several price indices (General Price Index INFL_GPIF, Wholesale price Index INF_WPI and GDP deflator INFL_DEF_AGG_Y). However, deflation did not ignite sustainable aggregate growth that remained erratic as captured by real GDP growth, total gross fixed capital formation (FBK_TOTAL_REAL_GROWTH) and private consumption real growth (HHS_CONS_REAL_GROWTH). In fact, deflation and the real appreciation of the Brazilian Real (seen in the upward trend of the real exchange rate, RER_DEV) until late 1998 produced an increasing deterioration in both the trade (BOP_TB) and the current account (BOP_CA) balances. Despite a growing ratio of tax revenues to GDP (CARGA), Public Sector fiscal primary surplus as a percent of GDP (FIN_PS_PRIM_Y) was clearly insufficient until a turnaround in policy in 1999, which aimed to stabilize the Government's domestic debt to GDP ratio (FIN_CG_DBT_DOM_Y). Following the standard models on currency crises, the risk of a change in market perception of the sustainability of the pegged Real was clearly growing by end 1997mid1998, particularly after the East Asian crises.

The macro model also depicts the 1999 financial crisis reasonably well in historical simulation mode. Stocks, issuance and holdings of the key financial asset (Government domestic bonds, FIN_CG_DBT_DOM) increase and interest payments (FIN_PS_INTPAY_REAL) jump. The model also captures adequately the increases in domestic prices (general price index, the CPI and the WPI) brought by the pass-through effect of the depreciation of the Real that follows it floating in January 1999 . The change in the exchange rate regime resulted in an average $56.4 \%$ depreciation of the average annual nominal exchange rate that translated --given the pass-though on domestic prices-- into a $35 \%$ real devaluation of the index (RER_DEV). The model also captures the fall of the domestic real interest rates that accompanied the surge in domestic prices after the crisis. Finally, the model overshoots slightly its imports projection although the expected correction in both the trade and the current account balances is picked up. 
Table 2(a): Some Results of the Macro Model, Historical Simulation for 1999

(Real Growth Rates in Percent, BoP results in USD Million, Employment results in units of workers)

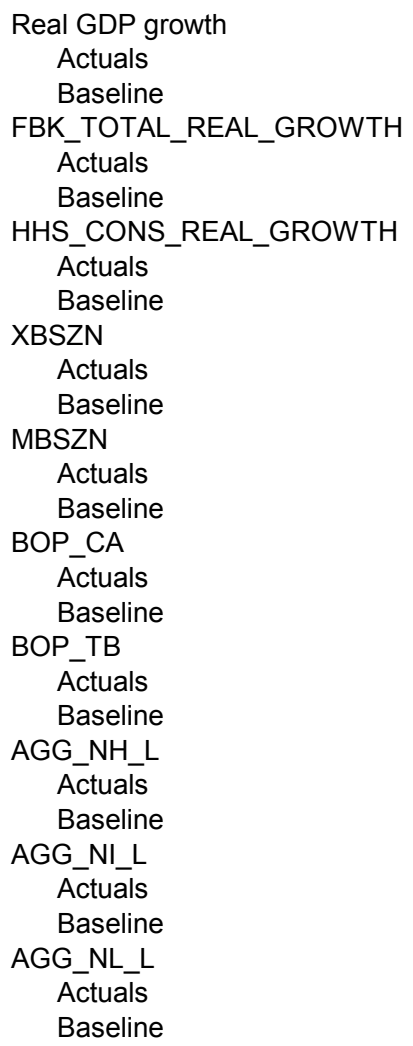

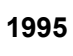

\section{2}

4.7

7.3

5.2

4.8

5.2

$49,916,655$

$47,834,680$

$61,314,054$

$59,486,390$

$-18,382$

$-18,173$

$-3,464$

$-2,660$

$4,076,944$

$4,073,141$

$22,762,114$

$22,245,900$

$27,075,090$

$26,260,380$
1996

2.7

1.9

1.2

$-3.6$

5.6

5.0

$54,430,127$

$57,002,630$

$69,310,584$

$68,346,620$

$-23,442$

$-20,762$

$-5,539$

$-1,045$

$4,298,040$

$4,279,046$

$24,027,848$

$24,340,140$

$24,592,552$

$24,462,200$
1997

3.3

0.3

9.3

0.2

3.3

0.9

$65,356,311$

$65,265,190$

$86,000,488$

$85,603,290$

$-30,555$

$-29,613$

$-6,856$

$-7,317$

$4,590,574$

$4,544,963$

$24,756,877$

$25,658,480$

$24,886,158$

$25,116,370$
1998

0.1

0.7

$-0.3$

2.5

$-1.5$

$-0.2$

$67,862,415$

$70,423,570$

$87,768,795$

$84,773,800$

$-33,435$

$-26,205$

$-6,594$

$-2,091$

$4,924,643$

$4,918,456$

$25,971,134$

$25,778,510$

$24,110,653$

$24,350,920$
1999

0.8

0.5

$-7.2$

$-6.1$

0.5

$-0.8$

$100,135,527$

$103,217,900$

$115,153,991$

$123,693,100$

$-25,335$

$-29,205$

$-1,199$

$-3,608$

$4,975,319$

$5,080,301$

$27,121,571$

$26,534,570$

$23,777,927$

$23,894,390$

Source: Authors' estimates based on Pereira da Silva, Picchetti and Samy de Castro (2004) 
Table 2(b): Major Results of the Public Sector Financial Sector Modules, Historical Simulation for 1999 (Tax and Fiscal results in Percent of GDP, Debt results in current BRL Million, Inflation results in Percent)

\begin{tabular}{|c|c|c|c|c|c|}
\hline & 1995 & 1996 & 1997 & 1998 & 1999 \\
\hline \multicolumn{6}{|c|}{ AGG_TAX_TRIB_REAL } \\
\hline Actuals & 18.65 & 17.96 & 18.19 & 18.48 & 20.37 \\
\hline Baseline & 17.08 & 18.27 & 20.18 & 19.67 & 19.50 \\
\hline \multicolumn{6}{|c|}{ AGG_TAX_INSS_REAL } \\
\hline Actuals & 5.92 & 7.13 & 6.01 & 7.37 & 7.34 \\
\hline Baseline & 6.04 & 7.22 & 6.19 & 7.46 & 7.40 \\
\hline \multicolumn{6}{|c|}{ AGG TAX OTH REAL } \\
\hline Actuals & 3.92 & 3.50 & 4.37 & 3.46 & 3.33 \\
\hline Baseline & 4.00 & 3.54 & 4.50 & 3.50 & 3.36 \\
\hline \multicolumn{6}{|l|}{ CARGA } \\
\hline Actuals & 28.44 & 28.63 & 28.58 & 29.33 & 31.07 \\
\hline Baseline & 27.12 & 29.03 & 30.86 & 30.63 & 30.26 \\
\hline \multicolumn{6}{|c|}{ FIN_TR_PRIM_Y } \\
\hline Actuals & -0.58 & -0.42 & -0.60 & -1.60 & -3.13 \\
\hline Baseline & 0.47 & -1.10 & -1.50 & -2.17 & -2.56 \\
\hline \multicolumn{6}{|c|}{ FIN_CG_INTPAY_Y } \\
\hline Actuals & 2.90 & 2.93 & 2.36 & 5.95 & 9.13 \\
\hline Baseline & 4.40 & 3.13 & 2.27 & 5.96 & 7.33 \\
\hline \multicolumn{6}{|c|}{ FIN_PS_PRIM_Y } \\
\hline$\overline{\text { Actuals }}$ & -0.27 & 0.09 & 0.95 & -0.01 & -3.19 \\
\hline Baseline & 1.59 & -0.31 & -0.24 & -0.67 & -2.31 \\
\hline \multicolumn{6}{|c|}{ FIN_PS_INTPAY_REAL } \\
\hline Actuals & 96,325 & 80,037 & 74,040 & 115,172 & 181,344 \\
\hline Baseline & 119,859 & 83,422 & 69,630 & 111,567 & 146,627 \\
\hline \multicolumn{6}{|c|}{ FIN GG DBT DOM } \\
\hline$\overline{\text { Actuals }}$ & 136,904 & 206,068 & 261,842 & 317,212 & 394,441 \\
\hline Baseline & 168,963 & 182,763 & 238,856 & 320,860 & 383,905 \\
\hline \multicolumn{6}{|c|}{ FIN_CG_DBT_DOM_Y } \\
\hline Actuals & 9.84 & 14.40 & 16.79 & 20.92 & 22.07 \\
\hline Baseline & 13.34 & 10.75 & 15.80 & 22.24 & 21.93 \\
\hline \multicolumn{6}{|l|}{ INFL_WPI } \\
\hline Actuals & 58.77 & 6.33 & 8.13 & 3.55 & 16.58 \\
\hline Baseline & 66.53 & 8.32 & 8.66 & 5.89 & 15.25 \\
\hline \multicolumn{6}{|c|}{ INFL_DEF_AGG_Y } \\
\hline Actuals & 77.55 & 17.41 & 8.25 & 4.85 & 5.70 \\
\hline Baseline & 76.91 & 17.68 & 7.83 & 5.03 & 6.36 \\
\hline \multicolumn{6}{|l|}{ INFL_GPIF } \\
\hline Actuals & 14.78 & 9.34 & 7.48 & 1.70 & 19.98 \\
\hline Baseline & 14.78 & 9.34 & 7.48 & 1.70 & 19.98 \\
\hline \multicolumn{6}{|l|}{ RER_DEV } \\
\hline Actuals & -7.22 & 5.43 & -0.82 & 1.37 & 35.27 \\
\hline Baseline & -11.55 & 3.49 & -1.30 & 0.87 & 36.82 \\
\hline \multicolumn{6}{|c|}{ Real Interest Rate, Certificates of Deposit } \\
\hline Actuals & 32.40 & 15.60 & 15.60 & 25.30 & 4.40 \\
\hline Baseline & 29.69 & 15.39 & 15.01 & 23.97 & 5.33 \\
\hline \multicolumn{6}{|l|}{ WC_REAL } \\
\hline $\bar{A}$ ctuals & 75.21 & 33.46 & 28.39 & 32.06 & 12.21 \\
\hline Baseline & 75.21 & 33.46 & 28.39 & 32.06 & 12.21 \\
\hline \multicolumn{6}{|l|}{ SELIC_REAL } \\
\hline Actuals & 33.40 & 16.50 & 16.10 & 26.60 & 4.70 \\
\hline Baseline & 33.37 & 16.53 & 16.09 & 26.63 & 4.68 \\
\hline
\end{tabular}

Source: Authors' estimates based on Pereira da Silva, Picchetti and Samy de Castro (2004) 


\section{Generating the LAVs to link the macro and micro models}

As indicated earlier, the factor markets module of the macroeconomic model generates 20 LAVs for occupational status (three employment levels, by sector, and one unemployment level, for five area/skill combinations), 15 LAVs for incomes (the earnings rates in each sector, in each of the five area/skill combinations). ${ }^{11}$ In addition, there are also six LAVS for changes in the output prices of the six sectors. There are thus $41 \mathrm{LAVs}$ in total. The LAVs were generated by area (Urban and Rural); by skills: low (0-4 years of schooling); intermediate (5-11 years of schooling) and high (12 or more years of schooling); and by occupational sector (tradable, non tradable and informal). Tables 3 and 4 below show the estimates produced using the macro model runs for 1999, the actual observed at the PNAD 1998 and 1999 data, and also the errors produced by the macro model.

The storyline for the 1998-1999 crisis is well-known: the financial crisis resulted in an overall decline in urban employment across the country. Unemployment grew in both urban and rural areas, and for all skill levels, but more markedly for high-skill workers. Informality also grew, particularly in urban areas. Formal employment fell across all skill groups in urban areas, and more markedly in non-tradable sectors, as one would expect. In rural areas, however, the real currency depreciation produced a positive output response leading to an increase in employment in the tradable sectors for all skill groups.

Table 3 presents the occupational structure of the Brazilian population, aggregated by these three sectors and three skill groups, for both urban and rural areas. Column (A) shows absolute numbers and proportions for 1998, and column (B) shows the same information as actually observed in 1999, and calculates the actual changes between the two years, which we sometimes refer to as the "true LAVs". Column (C) presents the corresponding prediction results from the macro module for 1999. The entries in this column are counterfactual occupational numbers and shares, as predicted by the model, when calibrated to simulate the crisis, on the basis of 1998 data. It includes the "model LAVs", i.e. the predicted change in employment shares in each category. The last column in the table subtracts the actual LAVs (in column B) from the predicted LAVs (in column C), and thus measure the absolute errors of the macro model in predicting occupational change.

On the whole, the model gets the directions of change right: there are only four errors of direction, corresponding to $20 \%$ of the simulations. Three of these errors were in rural areas, where our overall confidence on the underlying data is lower in any case. In terms of precision, however, the macro module performs rather poorly. Ten $(50 \%)$ predictions are off by five percentage points or more, in absolute

\footnotetext{
${ }^{11}$ Recall that there are only five area/skill combinations because the intermediate and high-skill workers in rural areas are being considered together, due to an insufficient number of observations.
} 
terms. In relative terms, the errors are very large indeed, and on seven occasions greater than $100 \%$, with respect to the actual changes.

Table 3: Aggregate results from the macro models - Occupations

\begin{tabular}{|c|c|c|c|c|c|c|c|c|c|}
\hline \multirow[b]{2}{*}{$\begin{array}{l}\text { Overall Occupational / } \\
\text { Employment with the } \\
\text { unemployed }\end{array}$} & \multicolumn{2}{|c|}{$\begin{array}{l}1998 \text { Actual from PNAD } \\
\text { (A) }\end{array}$} & \multicolumn{3}{|c|}{$\begin{array}{l}1999 \text { Actual from PNAD } \\
\text { (B) }\end{array}$} & \multicolumn{3}{|c|}{$\begin{array}{l}1999 \\
\text { simulated by the Macro Model only } \\
\text { (c) }\end{array}$} & \multirow{2}{*}{\begin{tabular}{|l}
$\begin{array}{c}\text { Errors of the } \\
\text { Macro Model }\end{array}$ \\
Absolute Error
\end{tabular}} \\
\hline & Units of workers & $\begin{array}{c}\text { Percentage } \\
\text { of workers by } \\
\text { category }\end{array}$ & Units of workers & $\begin{array}{l}\text { Percentage } \\
\text { of workers by } \\
\text { category }\end{array}$ & $\begin{array}{c}\text { Actuals } \\
\text { Oberved } \\
\text { Changes } \\
\text { (True LAVs) }\end{array}$ & Units of workers & $\begin{array}{l}\text { Percentage } \\
\text { of workers by } \\
\text { category }\end{array}$ & $\begin{array}{l}\text { Percent } \\
\text { Change in } \\
\text { each } \\
\text { category } \\
\text { (LAVs as in } \\
\text { Table 3) }\end{array}$ & \\
\hline Urban sector & $48,809,911$ & & $50,317,141$ & & & $51,620,283$ & & & \\
\hline Low skill & $17,372,833$ & $54.6 \%$ & $17,259,832$ & & & $18,043,135$ & $56.0 \%$ & & \\
\hline unemployed & $1,497,575$ & $4.7 \%$ & $1,606,782$ & $5.1 \%$ & $8.49 \%$ & $1,623,210$ & $5.0 \%$ & $6.93 \%$ & $-1.56 \%$ \\
\hline formal tradable sector & $2,184,630$ & $6.9 \%$ & $2,071,504$ & $6.6 \%$ & $-4.08 \%$ & $2,112,696$ & $6.6 \%$ & $-4.58 \%$ & $-0.51 \%$ \\
\hline formal tradable sector & $4,345,438$ & $10.9 \%$ & $4,475,094$ & $10.7 \%$ & $-1.65 \%$ & $4,556,787$ & $10.9 \%$ & $-0.22 \%$ & $1.44 \%$ \\
\hline formal non tradable sector & $7,809,610$ & $19.6 \%$ & $7,923,915$ & $18.9 \%$ & $-3.12 \%$ & $7,872,205$ & $18.8 \%$ & $-4.06 \%$ & $-0.94 \%$ \\
\hline Informal sector & $10,774,217$ & $27.0 \%$ & $11,509,694$ & $27.5 \%$ & $2.00 \%$ & $11,596,700$ & $27.6 \%$ & $2.44 \%$ & $0.44 \%$ \\
\hline High skill & $4,804,125$ & $79.2 \%$ & $4,903,569$ & & & $5,286,195$ & $79.3 \%$ & & \\
\hline unemployed & 321,052 & $5.3 \%$ & 380,467 & $6.1 \%$ & $14.56 \%$ & 381,562 & $5.7 \%$ & $8.26 \%$ & $-6.29 \%$ \\
\hline formal tradable sector & 709,379 & $11.7 \%$ & 723,085 & $11.5 \%$ & $-1.54 \%$ & 782,972 & $11.8 \%$ & $0.53 \%$ & $2.07 \%$ \\
\hline formal non tradable sector & $2,274,160$ & $37.5 \%$ & $2,217,602$ & $35.3 \%$ & $-5.76 \%$ & $2,323,764$ & $34.9 \%$ & $-6.92 \%$ & $-1.15 \%$ \\
\hline Informal sector & $1,499,534$ & $24.7 \%$ & $1,582,415$ & $25.2 \%$ & $2.02 \%$ & $1,797,897$ & $27.0 \%$ & $9.25 \%$ & $7.23 \%$ \\
\hline Rural sector & $10,049,477$ & & $10,267,135$ & & & $10,415,081$ & & & \\
\hline Low skill & $7,522,219$ & $68.8 \%$ & $7,484,557$ & & & $7,649,800$ & $71.0 \%$ & & \\
\hline unemployed & 174,659 & $1.6 \%$ & 176,238 & $1.7 \%$ & $3.75 \%$ & 180,065 & $1.7 \%$ & $3.10 \%$ & $-0.65 \%$ \\
\hline formal tradable sector & 958,768 & $8.8 \%$ & 984,502 & $9.3 \%$ & $5.94 \%$ & 942,946 & $8.8 \%$ & $-1.65 \%$ & $-7.59 \%$ \\
\hline formal non tradable sector & 365,199 & $3.3 \%$ & 347,372 & $3.3 \%$ & $-1.80 \%$ & 340,327 & $3.2 \%$ & $-6.81 \%$ & $-5.01 \%$ \\
\hline
\end{tabular}

Source: Authors' estimates based on PNAD/IBGE 1998/1999

Table 4 presents the results in terms of changes in nominal earnings (labor incomes). As expected, output contraction in urban areas translated not only into falls in employment (as seen in Table 3), but also in falling wages (even in nominal terms). Interestingly, this was the case for all categories, except workers with low or intermediate skills in the formal non-tradable sector. In rural areas, there was a much more mixed picture. Interestingly, there were large actual rises in the wages of all workers in the formal non-tradable sector. For low-skilled workers, this rise was of $32 \%$ in nominal terms, and well-predicted by the model. Conversely, wages in the rural formal tradable sector fell marginally. 
As in Table 3, Table 4 allows us to judge the performance of the macro model, by comparing the predicted changes in wages for each worker category (the model LAVs in column E), with the changes actually observed (the "true LAVs" in column D). Absolute errors are once again presented in column F. Fortunately, the performance of the macro model for earnings is better than for occupations. None of the 15 counterfactual changes in earnings for household groups reported went in the opposite direction to the changes actually observed for those groups.

Table 4: Aggregate results from the macro model - Earnings

\begin{tabular}{|c|c|c|c|c|c|c|}
\hline & \multicolumn{3}{|c|}{$\begin{array}{c}\text { Wage (non-zero earnings) in nominal BRL per } \\
\text { month }\end{array}$} & \multicolumn{2}{|c|}{$\begin{array}{l}\text { Linkage Aggregate Variables } \\
\text { (LAVs) in percent change for } \\
\text { each category for 1998/1999 }\end{array}$} & \multirow[b]{2}{*}{$\begin{array}{l}\text { Error } \\
\text { (F) }\end{array}$} \\
\hline & $\begin{array}{l}1998 \text { Actual } \\
\text { from PNAD } \\
\text { (A) }\end{array}$ & $\begin{array}{l}1999 \text { Actual } \\
\text { from PNAD } \\
\text { (B) }\end{array}$ & $\begin{array}{c}1999 \\
\text { simulated by } \\
\text { the Macro } \\
\text { Model only } \\
\text { (C) }\end{array}$ & $\begin{array}{c}\text { Actuals } \\
\text { Oberved } \\
\text { Changes (True } \\
\text { LAVs) } \\
\text { (D) } \\
\end{array}$ & $\begin{array}{l}\text { LAVs Macro } \\
\text { Model } \\
\text { (E) } \\
\end{array}$ & \\
\hline \multicolumn{7}{|l|}{ Urban Sector } \\
\hline \multicolumn{7}{|l|}{ Low skill } \\
\hline formal tradable & 454.67 & 450.81 & 449.94 & $-0.85 \%$ & $-1.04 \%$ & $-0.19 \%$ \\
\hline formal non tradable & 385.27 & 404.02 & 439.01 & $4.87 \%$ & $13.95 \%$ & $9.08 \%$ \\
\hline Informal & 264.53 & 259.82 & 258.76 & $-1.78 \%$ & $-2.18 \%$ & $-0.40 \%$ \\
\hline average for the category & 316.34 & 314.77 & 317.38 & $-0.49 \%$ & $0.33 \%$ & $0.82 \%$ \\
\hline \multicolumn{7}{|l|}{ Intermediate skill } \\
\hline formal tradable & 627.25 & 605.30 & 541.31 & $-3.50 \%$ & $-13.70 \%$ & $-10.20 \%$ \\
\hline formal non tradable & 546.28 & 547.12 & 548.47 & $0.15 \%$ & $0.40 \%$ & $0.25 \%$ \\
\hline Informal & 398.91 & 388.51 & 385.44 & $-2.61 \%$ & $-3.38 \%$ & $-0.77 \%$ \\
\hline average for the category & 492.46 & 481.73 & 468.42 & $-2.18 \%$ & $-4.88 \%$ & $-2.70 \%$ \\
\hline \multicolumn{7}{|l|}{ High skill } \\
\hline formal tradable & $2,011.96$ & $1,997.40$ & $1,869.99$ & $-0.72 \%$ & $-7.06 \%$ & $-6.33 \%$ \\
\hline formal non tradable & $1,759.46$ & $1,682.85$ & $1,678.20$ & $-4.35 \%$ & $-4.62 \%$ & $-0.26 \%$ \\
\hline Informal & $1,391.10$ & $1,327.12$ & $1,315.27$ & $-4.60 \%$ & $-5.45 \%$ & $-0.85 \%$ \\
\hline average for the category & $1,676.54$ & $1,608.90$ & $1,575.78$ & $-4.03 \%$ & $-6.01 \%$ & $-1.98 \%$ \\
\hline \multicolumn{7}{|l|}{ Rural sector } \\
\hline \multicolumn{7}{|l|}{ Low skill } \\
\hline formal tradable & 341.14 & 337.88 & 322.60 & $-0.96 \%$ & $-5.44 \%$ & $-4.48 \%$ \\
\hline formal non tradable & 252.03 & 333.78 & 333.50 & $32.44 \%$ & $32.33 \%$ & $-0.11 \%$ \\
\hline Informal & 164.69 & 172.02 & 171.47 & $4.45 \%$ & $4.12 \%$ & $-0.34 \%$ \\
\hline average for the category & 192.83 & 202.52 & 197.93 & $5.02 \%$ & $2.64 \%$ & $-2.38 \%$ \\
\hline \multicolumn{7}{|l|}{ Intermediate + High skill } \\
\hline formal tradable & 551.13 & 529.68 & 507.13 & $-3.89 \%$ & $-7.98 \%$ & $-4.09 \%$ \\
\hline formal non tradable & 527.82 & 593.85 & 684.36 & $12.51 \%$ & $29.66 \%$ & $17.15 \%$ \\
\hline Informal & 275.19 & 273.70 & 266.69 & $-0.54 \%$ & $-3.09 \%$ & $-2.55 \%$ \\
\hline average for the category & 380.28 & 389.10 & 385.50 & $2.32 \%$ & $1.37 \%$ & $-0.95 \%$ \\
\hline
\end{tabular}

Source: Authors' estimates based on PNAD/IBGE 1998/1999

There were, however, four significant errors in magnitude of change --more than five percentage points in magnitude-- in the urban sector. The nominal monthly wages of workers with low level of skills working in the formal tradable sector were projected to grow by $13.9 \%$ : instead they grew only by $5 \%$. For 
intermediate skills workers in the formal tradable sector we projected to fall by $14.0 \%$ but they fell by $4 \%$. For workers with high level of skills working in the formal tradable sector we projected to fall by $7.0 \%$ and they fell only by $0.7 \%$. Finally in the rural sector for workers with intermediate and high level of skills in the formal tradable rural sector we projected to grow by $29.7 \%$ but they grew by $12.5 \%$. The macro model tends systematically to predict larger declines in wages than the ones that workers actually got. In the rural areas, the under-prediction affects only intermediate and high-skilled workers. Nevertheless, in onethird of the cases, prediction errors were quite low in absolute terms, and less than $20 \%$ in relative terms.

Overall, while the performance of the macro model in predicting short-term changes in the occupational structure of the population between 1998 and 1999 was disappointing, the performance in terms of earnings changes was less poor. Predictions of changes in earnings which are accurate in direction and less than $20 \%$ off in magnitude may begin to be of some use for policymakers seeking to assess which groups may need in greater need of social protection during a crisis episode. Nevertheless, these are still very aggregate predictions, defined in terms of groups - such as "intermediate skill workers in the formal non-tradable sector" - which may not provide effective policy handles, say, for the design of safety nets. This is why we combine the macro model with the micro module: in order to allocate the average changes predicted for each representative group of households to actual individuals in the household survey sample. Let us now turn to the definition of the microeconomic model.

\section{The Microeconomic Model}

The occupational responses to a devaluation such as the one we are considering may differ between men and women within the same area/skill groups, or indeed across women with different numbers of children. It may also differ across workers with the same levels of education, but different age and experience profiles. Changes in earnings might be different depending on whether the informal nontradable sector job is in manufacturing in a unionized sector or in own-account service provision in an urban slum. In order to capture some of the sources of heterogeneity across the diverse population of individuals and households lumped into these groups of agents, we estimate a simple reduced form model of household income determination, which is based on Bourguignon, Ferreira and Lustig (1998) and Ferreira and Barros (1999). Once the model has been estimated ${ }^{12}$, it can be used to simulate individual and household responses to the sectoral mean changes (in employment probabilities and in earnings) predicted by the macro module, while respecting the conditional distribution of wages and employment on observed individual characteristics.

\footnotetext{
${ }^{12}$ While the macro model is estimated on aggregated time-series data, the micro model is estimated on a single cross-section of the household survey (PNAD, 1998). In both cases, identical definitions of skills and sectors are used, to guarantee a consistent mapping of individuals into groups.
} 
The model consists of three simple blocks. Since we are interested in a measure of welfare, the first block simply defines the household's income per capita, aggregating it across its components. The second block seeks to estimate a descriptive relationship between individual earnings and some of its observed determinants, while the third block estimates a relationship between occupational choice and some of its key correlates.

The first block, which is given by equation (6), simply defines household per capita income, by adding all labor incomes across occupations (indexed by $s$ ) and household members (indexed by $i$ ). The sum of non-labor incomes of the individuals in the household is represented by $y_{0 h}$. The size of the household is denoted $n_{h} . l_{i s}$ is an indicator variable that takes a value of one if household member $i$ works in sector $s$ and zero otherwise. At the simulation stage, non-labor incomes and public sector wages are assumed to remain constant in real terms (i.e. are deflated to 1999 using the CPI computed from September 1998 to September $1999^{13}$, which is equal to 1.0598$)$.

$$
y_{h}=\frac{1}{n_{h}}\left[\sum_{i=1}^{n_{h}} \sum_{s=1}^{3} I_{i s} w_{i h}^{s}+y_{0 h}\right]
$$

The second block of equations is represented by a set of standard Mincerian earnings regressions:

$$
\log w_{i h}=\alpha_{g s}+x_{i h} \beta_{g s}+\varepsilon_{i h}
$$

This equation relates the earnings $(w)$ of an individual $i$ in household $h$ to his or her observed $(X)$ and unobserved $(\varepsilon)$ characteristics in the standard manner. The model is estimated separately across occupations (denoted by $s$ ) and across area/skill household groups $(g){ }^{14}$ The population was partitioned into the same groups used in the macro model. There are three occupation sectors $s$ (Formal Tradable; Formal Non-Tradable; Informal). Household groups $g$ are defined by urban or rural locations, and along the educational dimension: low (0-4 years of schooling), intermediate (5-11 years of schooling) and high (12 or more years of schooling). However, as we did before in the macro model, we aggregate the individuals that live in rural areas with intermediate or high skills. In each of these groups, the vector $x$ includes the following characteristics: intercept, education (and its square), experience (and its square), occupation, race, Brazilian geographic regions and dummies for gender and metropolitan areas. The estimation results for all fifteen $(\mathrm{g}, \mathrm{s})$ groups are reported in Annex 1.

\footnotetext{
${ }^{13}$ September is the reference month of the survey.

14 The corresponding $g$ and s subscripts are dropped from the variables ( $w, x$, and $\varepsilon$ ) in equation (7) for simplicity.
} 
For our purposes, these regressions are interpreted merely as descriptions of multivariate correlations. The coefficients are not interpreted causally, as they are likely to be biased both due to selectivity and to the correlation between unobserved ability and some of the regressors. The key assumption we make and which allows the earnings equations to be used for the micro-simulations - is that any such selection and endogeneity biases are stable between 1998 and 1999.

The occupational choice model is defined in the last block. The constrained choice of occupation by the worker as a function of his household and individual characteristics is represented as:

$$
I_{j=s}=I\left(z_{i h} \gamma_{s}+\eta_{i h}>z_{i h} \gamma_{j}+\eta_{i h} \mid \forall j \neq s\right)
$$

where $I$ is an indicator function, which takes the value one if the inequality within the bracket holds, and zero otherwise. $Z$ is a vector of observed individual and household characteristics, and $\eta$ captures unobserved individual-level determinants of occupational choice. Elements of $Z$ include: education; labor market experience; gender; race; occupation of head; education of head; experience of head; race of head; Brazilian geographic regions; dummy if metropolitan area; housing status and a categorical variable for other incomes. This occupational choice model may be estimated empirically by means of a discrete choice model such as a multinomial logit, where the probability of choosing the category $s$ (inactivity; unemployment; work in the informal sector; work in the formal tradable sector and work in the formal nontradable sector) is modeled as:

$$
\operatorname{Pr}(j=s)=\frac{e^{z_{i h} \gamma_{s}}}{\sum_{j} e^{z_{i h} \gamma_{j}}}
$$

Six such models, with identical specifications, were estimated: one for household heads, another one for spouses, and a third for other household members; separately for rural and urban areas. Each individual makes that choice according to whether the criterion within the bracket is higher for that sector than for any of the other four. The parameter vector $y$ is specific to each occupation and can be interpreted in two different ways: either as a vector of the marginal utilities of each characteristic in $Z$, in the occupation $s$; or as a descriptive parameter of the distribution of observed occupations, conditional on the elements of $Z$. Note that the occupational choice model is written in the reduced form, i.e., it doesn't include the wage rate of individuals or family members in the vector $Z$ of explanatory variables. Marginal effects calculated from the estimation results for all six models are reported in Annex 1.

The model (7) - (9) is estimated on household-level data from the Pesquisa Nacional por Amostra de Domicilios (PNAD), which is fielded annually (except in Census years) by the Instituto Brasileiro de Geografia e Estatística (IBGE). We use the unit-record data for the 1998 survey - which had a sample size of 88,356 households (and 333,074 individuals) - and for the 1999 survey - which had a sample size 
of 91,523 households (and 340,986 individuals). The PNAD is the staple household survey for analysis of the Brazilian income distribution. It is representative for both urban and rural areas in all five Brazilian geographic regions, except in the North where, for cost-related reasons, rural areas are only fielded in the State of Tocantins. Income data from the PNAD does, however, suffer from considerable measurement error. The PNAD questionnaires, although much improved during the 1990s, still contain insufficient detail on capital incomes, production for own consumption and incomes in kind. As a result, there is some evidence that some incomes are under-reported, particularly in rural areas and this problem is more severe at both tails of the distribution. ${ }^{15}$ In what follows, we chose to include rural incomes for the sake of completeness of coverage. We urge the reader to beware, however, that the income levels reported are likely to reflect substantial measurement error. Additionally, we restrict our labor earnings estimations to the sample aged 15 to 80 years old.

After estimating the model, we use equations 7 to 9 (with the estimated coefficients reported in Annex 1 , and with the individual residual terms from the estimation) and equation 6 to simulate the effects of the 1998-1999 Brazilian crises on the distribution of household per capita incomes, poverty and inequality. We then compare the counterfactual distribution thus constructed with the original distribution taken from PNAD 1999.

Formally, the micro-simulations consist of finding the solution of the following system of 21 equations, using the 1998 PNAD data:

$$
\begin{aligned}
& I_{s}^{g}\left(z_{i h} \hat{\gamma}_{s}+\eta_{i h}^{s}>z_{i h} \hat{\gamma}_{j}+\eta_{i h}^{j} \mid \forall j \neq s\right)=f_{s}^{g} \ldots . . . \forall s, g \\
& \sum_{i \in g} \sum_{s \in g} \operatorname{Exp}\left(\hat{\alpha}_{g s}+x_{i h} \beta_{g}+\varepsilon_{i h}\right)=\pi_{s}^{g} \omega_{s}^{g} \ldots \ldots . . \forall g
\end{aligned}
$$

Equation (10) corresponds to the first six equations of the system: one for household heads, one for spouses, and one for other household members, by rural and urban areas. Equation (11) corresponds to the remaining 15 equations: The earnings regressions were separately estimated for each group (occupational choice, skills and area). This system would be over-identified if we allowed for more than one element in each vector $y$ to vary. We therefore solve it for 21 unknowns, exactly: six $y_{0}$ and $15 \alpha$ terms.

\footnotetext{
${ }^{15}$ See Ferreira, Lanjouw and Neri (2003) and Elbers, Lanjouw, Lanjouw and Leite (2001) for an assessment of these measurement problems, based on comparisons between the PNAD and an alternative Brazilian household survey, the Pesquisa de Padrões de Vida (PPV).
} 
The interpretation is the following. The first six equations - represented by (10) - require that the intercept term of the multinomial logit for occupation $s$ (relative to inactivity) be such that the fraction of the overall population who belong to household group $g$ and choose to work in occupation $s$ be equal to the share of the population (who belong to that household group) which is predicted by the "top" macroeconomic model to be employed in occupation $s, f_{s}^{g}{ }^{16}$ The remaining equations - represented by (11) - require that the intercept term of the earnings equation estimated for household group $g$ be such that the mean of the real wage in the counterfactual distribution be equal to the sector/group wage predicted by the factor markets module of the macroeconomic model, $\omega_{s}^{g}$.

The system is fully simultaneous, and it is solved numerically by the application of a Newton-Raphson algorithm, which essentially alters values of the twelve unknowns parameters progressively, so as to minimize the sum of squared differences between the left- and the right-hand sides of Equations (10) and (11). This procedure is analogous to the one used by Bourguignon, Robilliard and Robinson (2002). Like them, we offer no formal existence or uniqueness proofs for the equilibrium of the system. Like theirs too, our algorithm does converge to a seemingly plausible equilibrium.

Once the system of equations represented by equations (10) and (11) converges to a solution, the solution values for the $Y_{0}$ and $\boldsymbol{\alpha}$ vectors are substituted into equations (7) and (9). Equation (9) will determine the new distribution of occupations in the population which is consistent with the macroeconomic changes simulated by the macro model. Taking these counterfactual individual occupations into account, equation (7) determines the new predicted earnings for each employed worker. Equation (6) aggregates the new earnings distribution generating the final counterfactual distribution of household incomes. ${ }^{17}$ These simulated distributions are therefore consistent (by construction) both with the actual conditional earnings distributions and with the conditional occupational distribution observed in 1998 and with the predictions of the macroeconomic model for the effects of the devaluation on the Brazilian economy. In what follows, we call these distributions the counterfactual 1999 distributions, and compare them with the actual distributions observed in 1999.

\footnotetext{
${ }^{16}$ One difficulty is that, whereas the macro module allows for changes in the relative skill composition of labour demand when constructing the employment LAVs, this micro-simulation does not allow for changes in the educational level of the worker. This may be economically realistic for the short term, but it implies that there are six actual unknowns for potentially eighteen exogenous variables ( $f_{s}{ }^{g}$ targets). In the simulations, the adjustment occurs through the number of people left over for unemployment and inactivity from each skill category, which corresponds to a quantity closure to the labor market.

${ }^{17}$ It is important to bear in mind that these counterfactual distributions assume that a number of features of the population and economy remained constant at their 1998 levels. The spatial, racial, gender and educational composition of the population, the distribution of non-labor incomes, and the internal composition of the households are some of these features.
} 


\section{Results from the complete macro-micro simulation: employment and earnings rates}

The main results for the occupational simulations are presented in Table 5, for urban and rural areas by category of skill and by sector of occupation. Employment changes were simulated to target the new distribution of employment across all sectors but not the exact number of individuals in each segment. There are six columns $(A)$ to $(F)$ in this table. The first four columns $(A)$ to $(D)$ contain the observed data and the results of the model's simulations. Columns $(E)$ and $(F)$ analyze the errors of the procedure and decompose them into macro and micro error components.

Column (A), "1998 Actual from PNAD", gives the actual 1998 employment numbers and the distribution of workers by category of skill and occupational sector. Column (B) "1999 Simulated by the Macro Model only" presents the counterfactual 1999 (absolute and relative) employment numbers as predicted by the macro model only, and the proportional changes (the LAVs) implied by these numbers, with respect to the 1998 actual. These are the same LAVs which were presented earlier, in the penultimate column in Table 3. Column (C), "1999 Simulated by the Macro-micro Model", presents the corresponding counterfactual employment numbers and LAVs predicted by the full macro-micro model. Column (D), "1999 Actual from PNAD", presents the real employment numbers from the 1999 PNAD, and the proportional changes (the "true" LAVs) with respect to the actual 1998 figures (as in column B in Table 3).

Column (E), "Errors of the Macro-micro Simulation", analyzes the differences between the macro-micro simulations and the actual changes, in absolute terms. We look at errors of sign in the direction of change, and at over or under-predictions above a threshold of five percentage points. Column (F), "Total Error of the Macro-micro Simulation", reports the absolute errors in worker shares, and then decomposes them between what can be attributable to prediction errors from the macro model and those coming from the micro-simulation model.

Somewhat surprisingly, the performance of the integrated macro-micro model is far superior to that of the macro model alone. For occupations in the urban sector, the absolute error is less than five percentage points for all but three categories: the formal non-tradable sector for workers with low skills; the informal sector for workers with high skills and the informal sector with high skills. For occupations in the rural sector the macro-micro model also performed adequately, except for rural households in the formal non tradable sector, with workers with intermediate and high skills. 
Table 5: Detailed results from the Macro-micro models - Occupations by skill and sector

\begin{tabular}{|c|c|c|c|c|c|c|c|c|c|c|c|c|c|c|c|c|c|c|}
\hline \multirow[b]{2}{*}{$\begin{array}{l}\text { Overall Occupational I } \\
\text { Employment with the } \\
\text { unemployed }\end{array}$} & \multicolumn{2}{|c|}{$\begin{array}{l}1998 \text { Actual from PNAD } \\
\text { (A) }\end{array}$} & \multicolumn{3}{|c|}{\begin{tabular}{|c}
1999 \\
simulated by the Macro Model only \\
(B)
\end{tabular}} & \multicolumn{3}{|c|}{$\begin{array}{c}\text { simulated by the Micro-Macro Model } \\
\text { (C) }\end{array}$} & \multicolumn{3}{|c|}{$\begin{array}{l}1999 \text { Actual from PNAD } \\
\text { (D) }\end{array}$} & \multicolumn{4}{|c|}{$\begin{array}{c}\text { Errors of the Macro-Micro } \\
\text { Simulation } \\
\text { (E) }\end{array}$} & \multicolumn{3}{|c|}{$\begin{array}{l}\text { Total Error of the Macro-Micro Simulation (in \% } \\
\text { points) } \\
\text { (F) }\end{array}$} \\
\hline & $\begin{array}{l}\text { Units of } \\
\text { workers }\end{array}$ & $\begin{array}{l}\text { Percentage } \\
\text { of workers } \\
\text { by category }\end{array}$ & $\begin{array}{l}\text { Units of } \\
\text { workers }\end{array}$ & $\begin{array}{l}\text { Percentage } \\
\text { of workers } \\
\text { by category }\end{array}$ & $\begin{array}{l}\text { Percent } \\
\text { Change in } \\
\text { each } \\
\text { category } \\
\text { (LAVs sa in } \\
\text { Table 3) }\end{array}$ & $\begin{array}{l}\text { Units of } \\
\text { workers }\end{array}$ & $\begin{array}{l}\text { Percentage } \\
\text { of workers } \\
\text { by category }\end{array}$ & $\begin{array}{c}\text { Percent } \\
\text { Change in } \\
\text { each } \\
\text { category } \\
\text { predicted by } \\
\text { Macro-Micro } \\
\text { model }\end{array}$ & $\begin{array}{l}\text { Units of } \\
\text { workers }\end{array}$ & $\begin{array}{l}\text { Percentage } \\
\text { of workers } \\
\text { by category }\end{array}$ & $\begin{array}{c}\text { Actuals } \\
\text { Oberved } \\
\text { Changes } \\
\text { (True LAVs) }\end{array}$ & 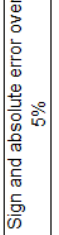 & 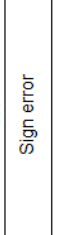 & 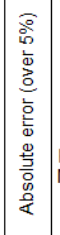 & \begin{tabular}{|c|} 
Total Error \\
(in units of \\
workers) \\
difference \\
between \\
units \\
predicted by \\
Macro-Micro \\
Model and \\
Actual
\end{tabular} & $\begin{array}{c}\text { difference } \\
\text { between } \\
\text { Percent } \\
\text { Change } \\
\text { predicted by } \\
\text { Macro-Micro } \\
\text { Model and } \\
\text { Actual }\end{array}$ & $\begin{array}{l}\text { Percentage of the Error } \\
\text { coming from the Macro } \\
\text { Model }\end{array}$ & $\begin{array}{l}\text { Percentage of } \\
\text { the Error } \\
\text { coming from } \\
\text { the Micro- } \\
\text { Simulation } \\
\text { Model }\end{array}$ \\
\hline $\begin{array}{l}\text { Urban sector } \\
\text { Low skill }\end{array}$ & \begin{tabular}{|l|}
$48,809,911$ \\
$17,372,833$
\end{tabular} & $54.6 \%$ & \begin{tabular}{|l|l}
$51,620,283$ \\
$18,043,135$
\end{tabular} & $56.0 \%$ & & $\begin{array}{l}49,119,235 \\
17,739,441\end{array}$ & $55.9 \%$ & & \begin{tabular}{l|l} 
& $50,317,141$ \\
$17,259,832$
\end{tabular} & & & & & & & & & \\
\hline unemploy & $1,497,575$ & $4.7 \%$ & $1,623,210$ & $5.0 \%$ & $6.93 \%$ & $1,602,373$ & $5.1 \%$ & $7.22 \%$ & $\begin{array}{l}1,606,782 \\
\end{array}$ & $5.1 \%$ & $8.49 \%$ & & & & $(4,409)$ & $-1.27 \%$ & $84.35 \%$ & $15.65 \%$ \\
\hline fort & 2,18 & $6.9 \%$ & 2,112 & $6.6 \%$ & $-4.58 \%$ & 2,081 & $6.6 \%$ & $-4.51 \%$ & $2,071,504$ & $6.6 \%$ & $-4.08 \%$ & & & & 9,978 & $-0.44 \%$ & $87.60 \%$ & $12.40 \%$ \\
\hline formal non tradable sector & $3,338,557$ & $10.5 \%$ & \begin{tabular}{|l}
$3,098,839$ \\
\end{tabular} & $9.6 \%$ & $-8.34 \%$ & $3,046,427$ & $9.6 \%$ & $-8.58 \%$ & $3,206,221$ & $10.2 \%$ & $-2.76 \%$ & & & & $(159,794)$ & $-5.82 \%$ & $95.94 \%$ & $4.06 \%$ \\
\hline Informal sector & $\mid \begin{array}{l}10,352,071 \\
\end{array}$ & $32.5 \%$ & $11,208,390$ & $34.8 \%$ & $6.87 \%$ & $11,009,159$ & $34.7 \%$ & $6.55 \%$ & $10,375,325$ & $33.0 \%$ & $1.38 \%$ & & & & 633,834 & $5.16 \%$ & $94.39 \%$ & $5.61 \%$ \\
\hline Intermediate skill & $26,632,953$ & $66.7 \%$ & $28,290,953$ & $67.4 \%$ & & $26,746,944$ & $67.3 \%$ & & $28,153,740$ & & & & & & & & & \\
\hline unempl & $3,703,688$ & $9.3 \%$ & $4,265,261$ & $10.2 \%$ & $9.62 \%$ & $4,060,079$ & $10.2 \%$ & $10.14 \%$ & $4,245,037$ & $10.2 \%$ & $9.49 \%$ & & & & $(184,958)$ & $0.65 \%$ & $19.95 \%$ & $80.05 \%$ \\
\hline able sector & $4,345,438$ & $10.9 \%$ & $4,556,787$ & $10.9 \%$ & $-0.22 \%$ & 4,280 & $10.8 \%$ & $-1.10 \%$ & $4,475,094$ & $10.7 \%$ & $-1.65 \%$ & & & & $(194$, & 0.5 & $61.86 \%$ & $38.14 \%$ \\
\hline formal non tradabl & $7,809,610$ & $19.6 \%$ & $7,872,205$ & $18.8 \%$ & $-4.06 \%$ & $7,411,419$ & $18.6 \%$ & $-4.65 \%$ & $7,923,915$ & $18.9 \%$ & -3.1 & & & & $(512$, & -1.5 & $61.50 \%$ & $38.50 \%$ \\
\hline Informal sector & $10,774,217$ & $27.0 \%$ & $11,596,700$ & $27.6 \%$ & $2.44 \%$ & $10,995,295$ & $27.7 \%$ & $2.52 \%$ & $11,509,694$ & $27.5 \%$ & $2.00 \%$ & & & & $(514,399)$ & $0.52 \%$ & $85.07 \%$ & $14.93 \%$ \\
\hline High sk & 4,804,125 & $79.2 \%$ & 5,2 & 79 & & 4 & 78 & & $4,903,569$ & & & & & & & & & \\
\hline unemployed & & $5.3 \%$ & 38 & $5.7 \%$ & $8.26 \%$ & 347,44 & $5.9 \%$ & $11.72 \%$ & 380,467 & $6.1 \%$ & $14.56 \%$ & & & & $(33,025)$ & $-2.84 \%$ & $64.54 \%$ & $35.46 \%$ \\
\hline formal tradable sector & 709,379 & 11. & 78 & & & & $11.6 \%$ & -0.6 & 723,085 & $11.5 \%$ & -1.5 & & & & $(39,624)$ & 0.9 & $64.70 \%$ & $35.30 \%$ \\
\hline formal non tradable sector & $2,274,160$ & $37.5 \%$ & $2,323,764$ & $34.9 \%$ & -6.92 & $2,015,842$ & $34.3 \%$ & -8.5 & $2,217,602$ & $35.3 \%$ & -5.7 & & & & $(201,760)$ & -2.8 & $41.06 \%$ & $58.94 \%$ \\
\hline Informal sector & $1,499,534$ & $24.7 \%$ & $1,797,897$ & $27.0 \%$ & $9.25 \%$ & $1,586,105$ & $27.0 \%$ & $9.15 \%$ & $1,582,415$ & $25.2 \%$ & $2.02 \%$ & & & 1 & 3,690 & $7.13 \%$ & $98.58 \%$ & $1.42 \%$ \\
\hline Rural sector & $\mid 10,049,477$ & & $10,415,081$ & & & $10,123,593$ & & & $10,267,135$ & & & & & & & & & \\
\hline Low skill & 7,522,219 & $68.8 \%$ & $7,649,800$ & $71.0 \%$ & & $7,595,335$ & $70.5 \%$ & & $\begin{array}{l}\text { 7,484,557 } \\
\end{array}$ & & & & & & 110,778 & $2.56 \%$ & $81.72 \%$ & $18.28 \%$ \\
\hline & & 1.6 & 180,065 & $1.7 \%$ & $3.10 \%$ & 182,6 & $1.7 \%$ & 6.2 & 176,2 & 1. & 3.7 & & & & & & & \\
\hline & & & & & & & & & & & & & & & & & & \\
\hline & 365,199 & & 3 & & -6.8 & 343,156 & & $-4.49 \%$ & 347,372 & 3. & $-1.80 \%$ & & & & & & & \\
\hline Informal sector & $6,023,593$ & $55.1 \%$ & $6,186,462$ & $57.4 \%$ & $2.70 \%$ & $6,112,215$ & $56.7 \%$ & $1.47 \%$ & $5,976,445$ & $56.4 \%$ & $2.36 \%$ & & & & 135,770 & $0.69 \%$ & $60.65 \%$ & $39.35 \%$ \\
\hline Intermediate + High skill & 2,527,258 & 66.5 & 2,76 & 67 & & 2, & 67 & & 2,7 & & & & & & & & & \\
\hline ur & 233 & 6 & 279 & 6. & $19.81 \%$ & 259,22 & $6.9 \%$ & $12.05 \%$ & 276,675 & 6.7 & 9.4 & & & & $(17$, & 2.6 & $59.80 \%$ & $40.20 \%$ \\
\hline formal tradable sector & 480,512 & 12.6 & 533,627 & $13.0 \%$ & $11.05 \%$ & 489,727 & $13.0 \%$ & $2.85 \%$ & 538,314 & $13.1 \%$ & $3.40 \%$ & & & & $(48,587)$ & $-0.55 \%$ & $78.97 \%$ & $21.03 \%$ \\
\hline formal non tradable sector & 424,539 & $11.2 \%$ & 399,930 & $9.8 \%$ & $-5.80 \%$ & 361,605 & $9.6 \%$ & $-14.06 \%$ & 470,756 & $11.4 \%$ & $2.33 \%$ & 1 & 1 & 1 & $(109,151)$ & $-16.38 \%$ & $91.59 \%$ & $8.41 \%$ \\
\hline Informal sector & $1,388,960$ & $36.6 \%$ & $1,552,270$ & $37.9 \%$ & $11.76 \%$ & $1,417,706$ & $37.6 \%$ & $2.98 \%$ & $1,496,833$ & $36.4 \%$ & $-0.55 \%$ & & 1 & & $(79,127)$ & $3.53 \%$ & $87.34 \%$ & $12.66 \%$ \\
\hline Total Urban and Rural & $58,859,388$ & & $62,035,364$ & & & $59,242,828$ & & & $60,584,276$ & & & 1 & 2 & & & & & \\
\hline
\end{tabular}

Source: Authors' estimates based on PNAD/IBGE 1998/1999 
Overall, out of the 20 occupational LAVs, the Macro-micro model makes six errors vis-à-vis the observed data (the "true LAVs") that are significant (hence about 30\% of the results). Two were errors in direction only; one was an error of both magnitude and direction; and three were errors of magnitude only. As column (F) indicates, the bulk of these errors can be attributed to the macro part of the model. This is clearly the major obstacle for these types of procedures, but the linkage with a macro model of some sort is nevertheless essential for simulating counterfactual economy-wide policies.

Still, the model seems to capture a good deal of the occupational effect of the 1999 crisis on the occupational structure in Brazil. The shock led to following key changes (change in actual observed data / change predicted by the macro-micro model):

(1) a significant increase $(+13 \% /+13 \%)$ in unemployment in both rural and urban areas;

(2) a particularly large rise in unemployment for workers with intermediate and high skill levels in urban areas $(+9.5 \% /+10 \%$ and $+15 \% /+12 \%$ respectively);

(3) an increase in the level of informality in both rural and urban areas $(+1 \% /+4 \%$ and $+4 \% / 9 \%$ respectively);

(4) a growth of informality in particular in urban areas for workers with intermediate and high levels of skills $(+2 \% /+2.5 \%$ and $+2 \% /+9 \%$ respectively $)$.

These four general characteristics are picked up fairly well by the macro-micro model, with the exception of an over-prediction for the increase in urban high-skill informality. Overall, it seems that the microsimulation stage of the procedure contributes to a considerable reduction in the prediction errors in occupations which plagued the macro stage, as reported in Table 3. Table 5 suggests that the predictions of the combined model do seem to capture the main general effects of the financial crisis on the Brazilian labor market. ${ }^{18}$ Naturally, these changes in occupational status were accompanied by changes in earnings. The Macro-micro model runs also the counterfactual simulation for earnings.

\section{c) The main results for the counterfactual structure of earnings (Table 6)}

The predictive performance of the macro-micro model simulations for earnings (non-zero nominal monthly wages) is presented in Table 6 below. Nominal monthly wages (in Brazilian Reais, BRL) are presented in Columns (A), (B), (E) and (F). The actual wages for 1998 and 1999 are in Columns (A) and (E) respectively. Columns $(B)$ and $(F)$ list the nominal monthly wages simulated by our macro component alone, and by the full macro-micro model, respectively.

\footnotetext{
${ }^{18}$ Whether or not we should derive much consolation from this improvement will depend on how much of it is caused simply by mechanical factors behind the convergence of the Newton-Raphson algorithm.
} 
For Brazil as a whole, the model seems to slightly underestimate absolute earnings levels in 1999. The errors reported in Table 6 are mostly small, and driven by the urban areas, which account for $80 \%$ of the population. The model tends to systematically predict larger declines in wages than were in fact observed. In the rural areas, the under-prediction affects only intermediate and high-skilled workers. For the six basic groupings underpinning Table 6 (the three skill levels in urban and rural areas), the model predictions really missed the target in only 5 out of 15 LAVs, leaving a record of about $66 \%$ success.

Overall, the macro-micro model can also be said to capture a great deal of the actually observed changes in earnings in Brazil, from 1998 to 1999. The shock led to following key changes. We present below the percentage change in actual observed data and in parentheses the percentage change predicted by the macro-micro model:

(1) Mean earnings fell for all three urban categories of workers; by $-0.49 \%(+0.33 \%)$ for workers with low skill level; by $-2.18 \%(-4.88 \%)$ for workers with intermediate skill level; by $-4.03 \%(-6.01 \%)$ for workers with high skill level;

(2) The picture is more mixed in rural areas. There, the only winners among low-skilled workers were those employed in the formal non-tradable and the informal sectors (and this is well predicted by the model). The main losers (-3.89\%) among intermediate and high skilled workers were those in the formal tradable sector (and this is over-predicted by the model, $-7.98 \%$ ). The main winners $(+12.51 \%)$ among intermediate and high skilled workers were those in the formal tradable sector (and this is over-predicted by the model, 29.66\%). 
Table 6: Aggregate results from the Macro-micro models - Earnings

\begin{tabular}{|c|c|c|c|c|c|c|c|c|c|c|c|c|c|}
\hline & \multicolumn{2}{|c|}{$\begin{array}{l}\text { Wage (non-zero } \\
\text { earnings) in nominal } \\
\text { BRL per month }\end{array}$} & \multicolumn{2}{|c|}{$\begin{array}{c}\text { Linkage Aggregate } \\
\text { Variables (LAVs) in } \\
\text { percent change for each } \\
\text { category for 1999/1999 }\end{array}$} & \multicolumn{2}{|c|}{$\begin{array}{l}\text { Wage (non-zero } \\
\text { earnings) in nominal } \\
\text { BRL per month }\end{array}$} & \multicolumn{7}{|c|}{ Total Error of the Macro-Micro Simulation } \\
\hline & $\begin{array}{l}1998 \text { Actual } \\
\text { from PNAD }\end{array}$ & $\begin{array}{c}1999 \\
\text { simulated by } \\
\text { the Macro } \\
\text { Model only } \\
\text { (B) }\end{array}$ & $\begin{array}{l}\text { LAVs as in } \\
\text { Table } 5\end{array}$ & $\begin{array}{c}\text { Actuals } \\
\text { Oberved } \\
\text { Changes } \\
\text { (True LAVs) } \\
\text { (D) }\end{array}$ & $\begin{array}{l}1999 \text { Actual } \\
\text { from PNAD }\end{array}$ & $\begin{array}{c}1999 \\
\text { simulated by } \\
\text { the Micro- } \\
\text { Macro } \\
\text { Model } \\
\text { (F) }\end{array}$ & $\begin{array}{l}\text { In nominal } \\
\text { BRL per } \\
\text { month }\end{array}$ & $\begin{array}{c}\text { difference } \\
\text { between } \\
\text { Percent } \\
\text { Change } \\
\text { predicted } \\
\text { by Macro- } \\
\text { Micro Model } \\
\text { and Actual }\end{array}$ & $\begin{array}{c}\text { Percentage } \\
\text { of the Error } \\
\text { coming } \\
\text { from the } \\
\text { Macro } \\
\text { Model }\end{array}$ & $\begin{array}{l}\text { Percentage } \\
\text { of the Error } \\
\text { coming } \\
\text { from the } \\
\text { Micro- } \\
\text { Simulation } \\
\text { Model }\end{array}$ & 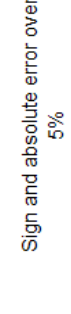 & $\begin{array}{l}\frac{5}{0} \\
\stackrel{5}{0} \\
\stackrel{5}{\omega}\end{array}$ & 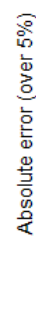 \\
\hline \multicolumn{14}{|l|}{$\begin{array}{l}\text { Urban Sector } \\
\text { Low skill }\end{array}$} \\
\hline formal tradable & 454.67 & 449.94 & $-1.04 \%$ & $-0.85 \%$ & 450.81 & 450.10 & -0.71 & $-0.16 \%$ & $84.70 \%$ & $15.30 \%$ & 0 & 0 & 0 \\
\hline formal non tradable & 385.27 & 439.01 & $13.95 \%$ & $4.87 \%$ & 404.02 & 438.88 & 34.86 & $8.63 \%$ & $99.64 \%$ & $0.36 \%$ & 0 & 0 & 1 \\
\hline Informal & 264.53 & 258.76 & $-2.18 \%$ & $-1.78 \%$ & 259.82 & 259.78 & -0.04 & $-0.02 \%$ & $51.01 \%$ & $48.99 \%$ & 0 & 0 & 0 \\
\hline average for the category & 316.34 & 317.38 & $0.33 \%$ & $-0.49 \%$ & 314.77 & 318.42 & 3.65 & $1.16 \%$ & $71.32 \%$ & $28.68 \%$ & 0 & 1 & 0 \\
\hline \multicolumn{14}{|l|}{ Intermediate skill } \\
\hline formal tradable & 627.25 & 541.31 & $-13.70 \%$ & $-3.50 \%$ & 605.30 & 540.31 & -64.99 & $-10.74 \%$ & $98.47 \%$ & $1.53 \%$ & 0 & 0 & 1 \\
\hline formal non tradable & 546.28 & 548.47 & $0.40 \%$ & $0.15 \%$ & 547.12 & 543.40 & -3.71 & $-0.68 \%$ & $21.13 \%$ & $78.87 \%$ & 0 & 0 & 0 \\
\hline Informal & 398.91 & 385.44 & $-3.38 \%$ & $-2.61 \%$ & 388.51 & 385.87 & -2.64 & $-0.68 \%$ & $87.69 \%$ & $12.31 \%$ & 0 & 0 & 0 \\
\hline average for the category & 492.46 & 468.42 & $-4.88 \%$ & $-2.18 \%$ & 481.73 & 466.54 & -15.19 & $-3.15 \%$ & $87.63 \%$ & $12.37 \%$ & 0 & 0 & 0 \\
\hline \multicolumn{14}{|l|}{ High skill } \\
\hline formal tradable & 2011.96 & 1869.99 & $-7.06 \%$ & $-0.72 \%$ & $1,997.40$ & $1,876.85$ & -120.55 & $-6.04 \%$ & $94.90 \%$ & $5.10 \%$ & 0 & 0 & 1 \\
\hline formal non tradable & 1759.46 & 1678.20 & $-4.62 \%$ & $-4.35 \%$ & $1,682.85$ & $1,674.90$ & -7.95 & $-0.47 \%$ & $58.48 \%$ & $41.52 \%$ & 0 & 0 & 0 \\
\hline Informal & 1391.10 & 1315.27 & $-5.45 \%$ & $-4.60 \%$ & $1,327.12$ & $1,321.97$ & -5.15 & $-0.39 \%$ & $63.90 \%$ & $36.10 \%$ & 0 & 0 & 0 \\
\hline average for the category & 1676.54 & 1575.78 & $-6.01 \%$ & $-4.03 \%$ & $1,608.90$ & $1,576.74$ & -32.16 & $-2.00 \%$ & $97.18 \%$ & $2.82 \%$ & 0 & 0 & 0 \\
\hline \multicolumn{14}{|l|}{ Rural sector } \\
\hline \multicolumn{14}{|l|}{ Low skill } \\
\hline formal tradable & 341.14 & 322.60 & $-5.44 \%$ & $-0.96 \%$ & 337.88 & 323.41 & -14.48 & $-4.28 \%$ & $94.96 \%$ & $5.04 \%$ & 0 & 0 & 0 \\
\hline formal non tradable & 252.03 & 333.50 & $32.33 \%$ & $32.44 \%$ & 333.78 & 334.18 & 0.40 & $0.12 \%$ & $29.46 \%$ & $70.54 \%$ & 0 & 0 & 0 \\
\hline Informal & 164.69 & 171.47 & $4.12 \%$ & $4.45 \%$ & 172.02 & 173.62 & 1.60 & $0.93 \%$ & $20.41 \%$ & $79.59 \%$ & 0 & 0 & 0 \\
\hline average for the category & 192.83 & 197.93 & $2.64 \%$ & $5.02 \%$ & 202.52 & 201.16 & -1.36 & $-0.67 \%$ & $58.66 \%$ & $41.34 \%$ & 0 & 0 & 0 \\
\hline \multicolumn{14}{|l|}{ Intermediate + High skill } \\
\hline formal tradable & 551.13 & 507.13 & $-7.98 \%$ & $-3.89 \%$ & 529.68 & 502.08 & -27.60 & $-5.21 \%$ & $81.71 \%$ & $18.29 \%$ & 0 & 0 & 1 \\
\hline formal non tradable & 527.82 & 684.36 & $29.66 \%$ & $12.51 \%$ & 593.85 & 650.29 & 56.44 & $9.50 \%$ & $72.65 \%$ & $27.35 \%$ & 0 & 0 & 1 \\
\hline Informal & 275.19 & 266.69 & $-3.09 \%$ & $-0.54 \%$ & 273.70 & 267.56 & -6.13 & $-2.24 \%$ & $88.92 \%$ & $11.08 \%$ & 0 & 0 & 0 \\
\hline average for the category & 380.28 & 385.50 & $1.37 \%$ & $2.32 \%$ & 389.10 & 379.77 & -9.33 & $-2.40 \%$ & $38.59 \%$ & $61.41 \%$ & 0 & 0 & 0 \\
\hline
\end{tabular}

Source: Authors' estimates based on PNAD/IBGE 1998/1999 


\section{Results from the macro-micro model: household incomes from three "experiments"}

Having thus described the results of the full macro-micro simulation in terms of group means for occupation and earnings rates, we now turn to the natural next step, which is to look at the predicted impacts on the disaggregated distribution of household income per capita. After all, had one been interested only in the changes in mean earnings for workers in each of those area / skill / sector groupings, the applied macroeconomic model might have sufficed. The whole point of integrating it with a micro-simulation module is to be able to better account for heterogeneities within those groups.

In this section, we present the disaggregated simulation results for household incomes, and compare them with the actual observed changes. In fact, in order to compare the performance of the fully integrated macro-micro model with alternative modeling strategies, we actually conduct three experiments. In the first experiment (Experiment 1), we mimic a "traditional" representative household group approach: the average effects of the 1999 shock are applied uniformly to all individuals belonging to the same representative group of households (RHG). However, instead of using the macro model's simulated results, we use the changes actually observed (the "true LAVs" from Tables 3 and 4), as if the macro model was capable of generating perfect predictions. This first experiment corresponds to the Representative Household Group (RHGs) approach used by most macro CGE models. The LAVs are the actual observed changes of average income and employment for each RHG. There is no microsimulation: each individual receives the average income and employment change of the RHG he/she belongs to.

In the second experiment (Experiment 2), we still use the observed changes in earnings and employment levels (the "true LAVs") but now, instead of imputing the LAVs uniformly to all members of a household group, we allow the microeconomic model to allocate them, by finding the solution to system (10)-(11). This takes heterogeneity in personal characteristics - observed and unobserved - into account. This second experiment corresponds to a pure simulation using the micro-simulation model. The micro model runs so that its average results for each RHG converge to the actual observed average income and employment change of the economy's RHGs. This experiment tests the predictive capability of the microsimulation model.

Finally, the third approach (Experiment 3), combines both previous approaches, i.e. the simulated results of the macro model with the functioning of the micro simulation model. This time the LAVs generated by the macroeconomic model are used instead of the observed ones, so that the third experiment corresponds to the full macro-micro linkage model. The macro simulation consists of running the macro model to replicate the 1999 financial crisis. The run generates LAVs consisting of simulated changes of 
average earnings and employment levels (as well as prices) for each RHG. Then the micro-simulation model runs so that its average results for each RHG converge to the simulated average income and employment change of the model's RHGs. This experiment tests the predictive capability of the full macro-micro linkage model.

The results for the distributions of household income per capita are used to construct three incidence curves for changes in nominal incomes. We compare the results of each of these three experiments with the actual observed changes in the distribution of household per capita income for Brazil between 1998 and 1999. The comparison is presented graphically in Figures 5, 6 and 7.

\section{a) Comparing the main results for the overall distribution for the three Experiments}

Figures 5, 6 and 7 present the income incidence curves resulting for the 1999 financial crisis on the distributions of household incomes in Brazil. In all cases, the curves plot the difference in logarithms of the mean incomes in each hundredth of the distribution. For instance the difference in logs between the actual 1999 and the actual 1998 incomes for each percentile of the distribution is given by the thick black line. That line constitutes the "benchmark" against which the curves of the three experiments will be assessed. Actual data shows that the 1999 financial crisis was inequality-decreasing. Apart from the first decile (where changes are often affected by the change in the proportion of households reporting zero incomes), the upper deciles of the distribution suffer much larger losses (real falls of 4 to $5 \%$ ) than the first deciles of the distribution, whose real losses are limited to about 1 to $2 \%$.

Figure 5 presents the comparison between the actual 1999/98 change in incomes for each percentile of the distribution and the incidence curve of the RHG experiment (Experiment 1). The model under this type of Experiment correctly predicted the fall in real incomes for the entire distribution, seen with respect to the line representing inflation during the period. Beyond that, the model substantially underestimates the rises in nominal earnings in the all segments of the distribution. In other words: it consistently overestimates the real wage losses during the crisis.

Figure 6 adds to the previous figure the incidence curve of the pure micro-simulation experiment (Experiment 2). This experiment performs much better: the distance between the predicted curve and the real change is much lower now, for the entire distribution and, in particular between the $50^{\text {th }}$ and $90^{\text {th }}$ deciles. Nevertheless, errors do remain, particular in the bottom half of the distribution and for the richest $5 \%$ of the population.

Figure 7 finally adds to the previous figure the incidence curve of the full Macro-micro-simulation experiment (Experiment 3). The integrated model performs better than the RHG simulations from 
Experiment 1, but not as well as Experiment 2. Since Experiment 2 was conducted using "true LAVs", its errors - i.e. the differences between its incidence curve and the thick line for the actual changes in Figures 5-7 - are due entirely to prediction errors from the micro-simulation model. The additional distance between the incidence curves from Experiments 3 and 2 correspond to additional errors arising from the macro module.

The important overall message we take away from Figure 7 - which in a sense graphically summarizes the main results of the paper - is that, while integrated macro-micro models like ours are not capable of perfectly predicting the incidence profile of a macroeconomic phenomenon such as the 1999 Brazilian currency crisis, nevertheless they perform reasonably well in predicting the direction of changes in earnings, and the broad pattern of their incidence along the income distribution. In particular, they perform much better than standard RHG approaches, even when macro errors in RHG approaches are eliminated (as they were here by the use of true LAVs for Experiment 1).

Figure 5 - Comparison between

Actual Observed Changes \&

Experiment 1 - using Representative Households Groups (RHG)

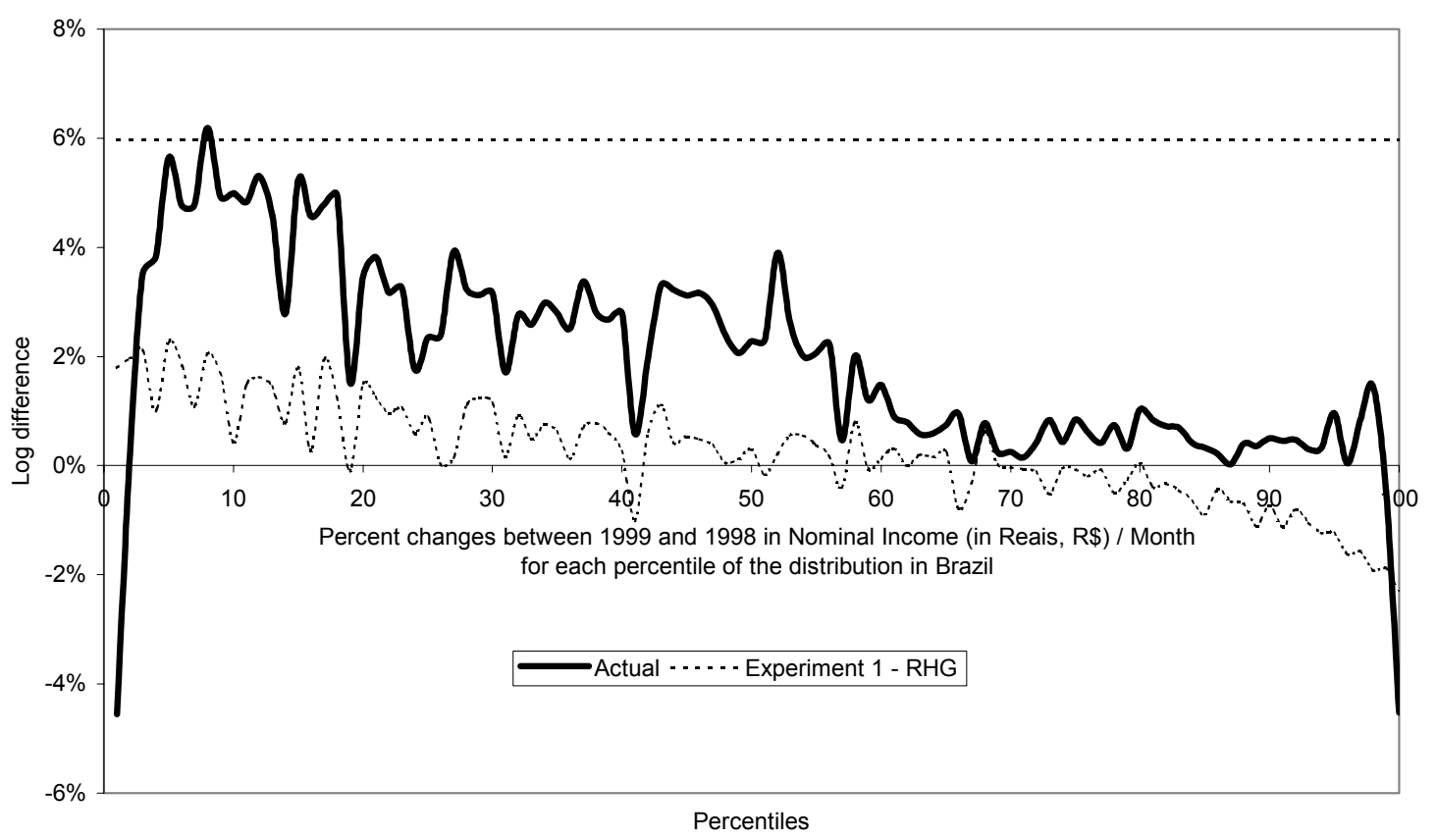

Source: Authors' estimates based on PNAD/IBGE 1998/1999 
Figure 6 - Comparison between

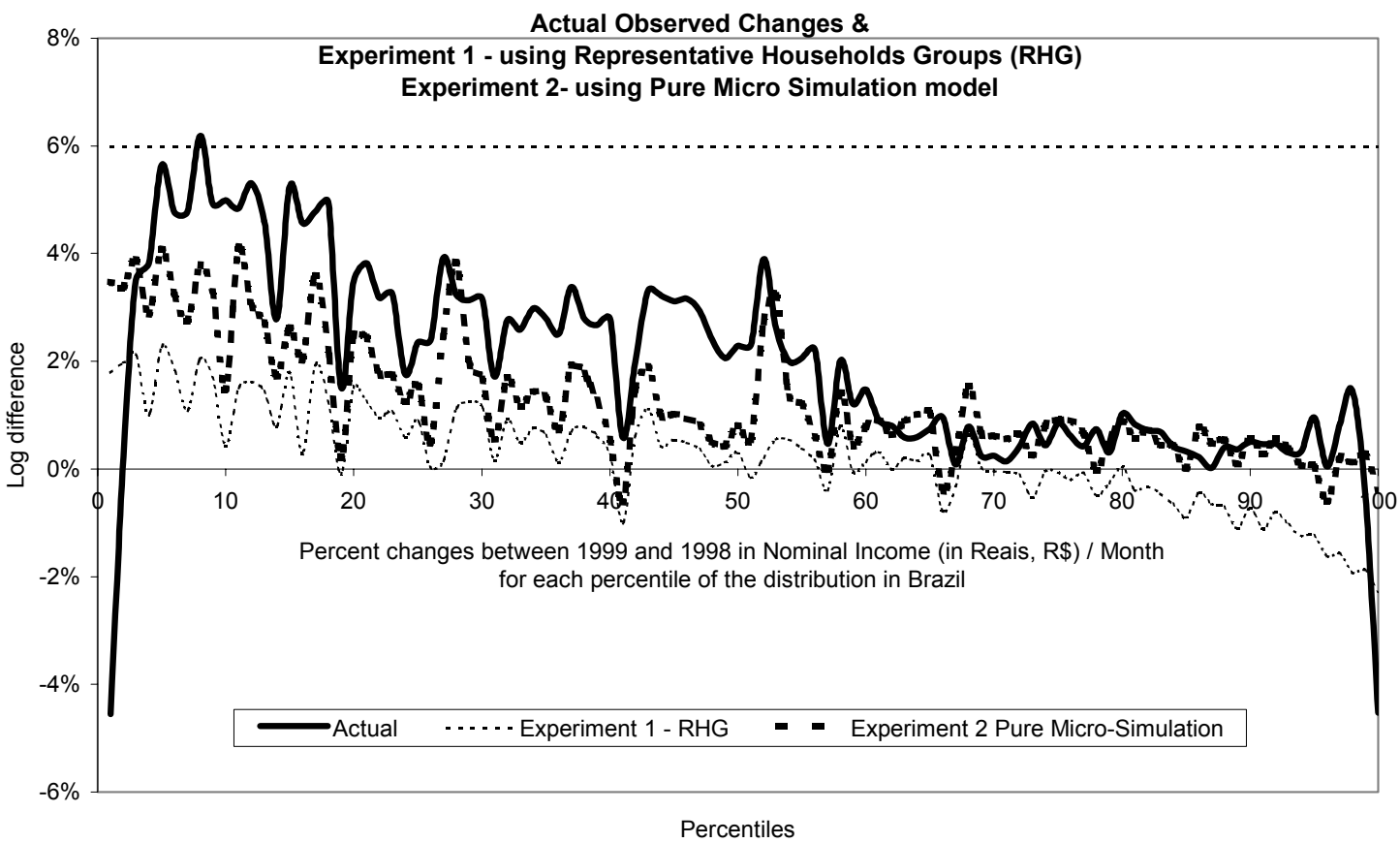

Source: Authors' estimates based on PNAD/IBGE 1998/1999

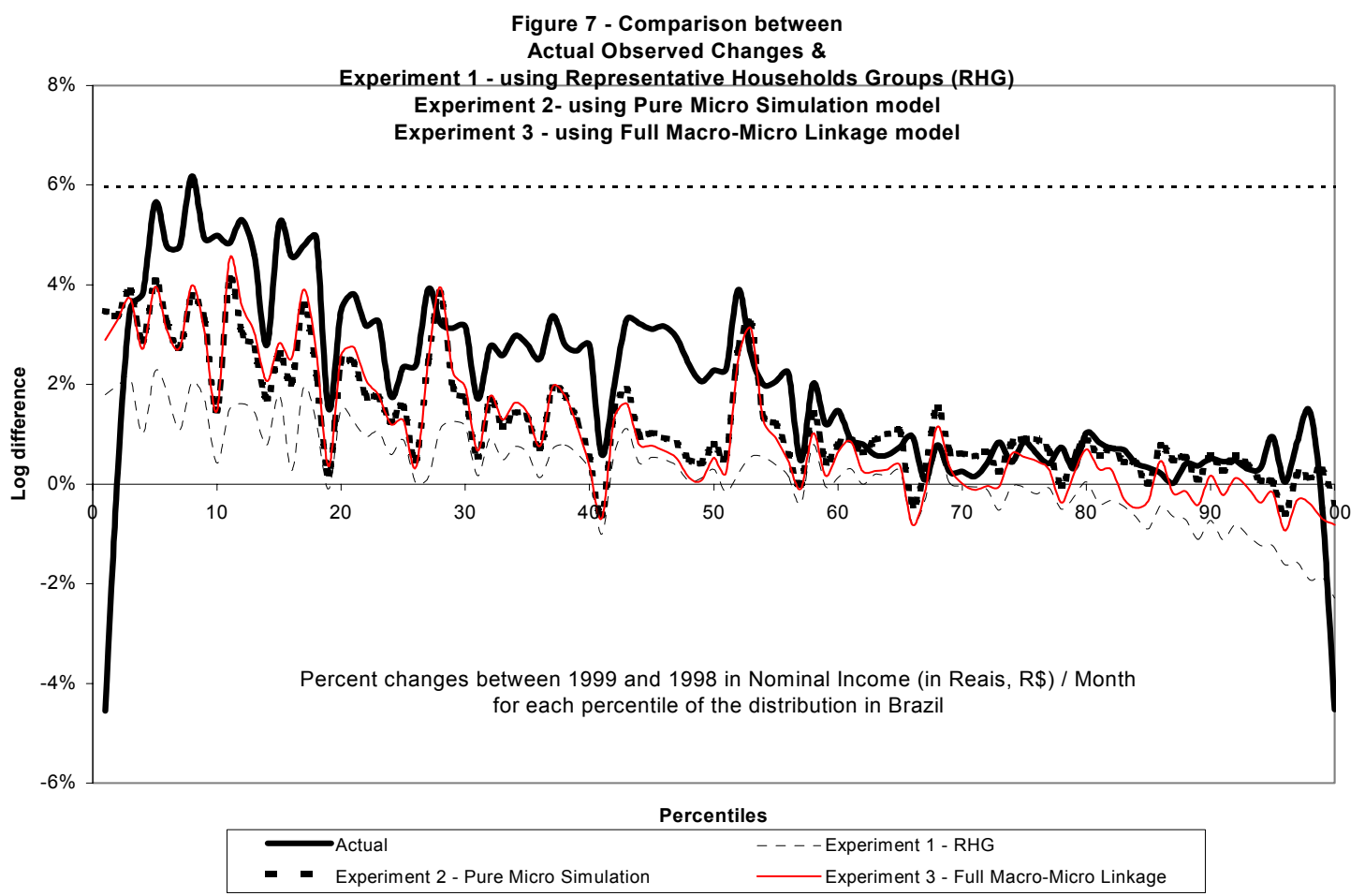

Source: Authors' estimates based on PNAD/IBGE 1998/1999 
All three incidence curves drawn on figures 5, 6 and 7 are derived from household survey data, one way or another. The line for actual changes is simply a line of differences between centile means across two surveys. The other three lines are predictions obtained by adding different amounts of income to those same means. In any case, these curves are clearly graphical representation of collections of sample statistics and, therefore, differences across them contain, in addition to modeling (prediction) errors, an element of sampling error. Strictly speaking, therefore, our preceding statements about differences should be subject to statistical tests for significance. The simplest suitable test is the paired $t$ test. In our exercise we have the same variable (income) measured under different ways on the same condition. Assuming that the incomes were generated from the same random sample it is easy to test the means. Treating the difference of the two variables as a random sample from a normal distribution the test is given by:

$\mathrm{H}_{0}: \mu_{\text {actual }}-\mu_{\operatorname{exp~i}}=0 \quad \mathrm{x} \quad \mathrm{H}_{1}: \mu_{\text {actual }}-\mu_{\exp } \neq 0$

$t=\frac{\left(\bar{x}-\mu_{0}\right) \sqrt{n}}{s} \sim t_{n-1}$

$s=\sqrt{\left(\sum_{i=1}^{n}\left(x_{i}-\bar{x}\right)^{2} / n-1\right)}$

Table 7 below presents the results of the paired $t$ test for statistical significance, for each one of the three experiments. At the $5 \%$ level of confidence, we can reject the null hypothesis $\mathrm{H}_{0}$ that the mean of the logarithms of the actual incomes and those simulated under experiment 1 are equal. We can not, however, reject the hypotheses that the lines representing experiments 2 and 3 - the micro-model based on true LAVs and the fully integrated macro-micro model, respectively - are equal to the line for the actually observed changes.

Table 7 Paired t test

\begin{tabular}{cccc}
\hline Hypothesis Test & $\mathrm{t}$ & $\mathrm{P}>|\mathrm{t}|$ & result \\
\hline $\mathrm{H}_{0}: \mu_{\text {actual }}=\mu_{\exp 1}$ & -2.7403 & 0.0073 & $\mathrm{H}_{0}$ rejected \\
$\mathrm{H}_{0}: \mu_{\text {actual }}=\mu_{\exp 2}$ & 0.3919 & 0.6959 & $\mathrm{H}_{0}$ accepted \\
$\mathrm{H}_{0}: \mu_{\text {actual }}=\mu_{\exp 3}$ & -0.3753 & 0.7082 & $\mathrm{H}_{0}$ accepted \\
\hline Source: Authors' estimates based on PNAD/IBGE 1998/1999
\end{tabular}

The interpretation of these test results is that, while the differences between the RHG simulations and the actual changes were too large to be due simply to sampling errors, the differences between the predictions from other two experiments and reality were small enough that they might be due simply to sampling error. Broadly similar results were also found using two alternative test formulations: the Welch test for samples from two different population distributions, and the Smirnov-Kolmogorov non-parametric test for distributional differences. In all three cases, the $p$-values for the null hypothesis under experiments 2 and 3 were higher than under experiment 1. 


\section{Concluding Remarks}

In this paper we outlined an integrated macro-micro model of the Brazilian economy, intended to investigate the link between macroeconomic shocks and the distributions of employment, earnings and household incomes. The approach was to estimate a macro-econometric model on time-series data, and a micro-econometric model on household-level cross-section data. The macroeconomic model generates three sets of linkage aggregate variables (LAVs): employment and unemployment levels per household group and sector, wage levels per household group and sector, and consumer price levels per sector. These linkage variables are then used to recalibrate parameters in the earnings and occupational models at the microeconomic level, and thus to simulate changes in the distribution of earnings and incomes at the household level.

This approach, adapted from Bourguignon, Robilliard and Robinson (2002), was applied to an investigation of the employment, earnings and income distribution effects of the 1998/99 devaluation of the Brazilian Real. Unlike previous studies that we are aware of, we took advantage of the benefit of hindsight, and compared the counterfactual distributions generated by our model for 1999 with the distributions actually observed in 1999.

The shock observed - together with the standard policy response of tightening both the monetary and fiscal stances to ensure price stability after a the currency floated - was expected to be rather negative. However, the massive devaluation in Brazil (nominal 56\%) did not result - as it did in East Asia - in a collapse of the financial sector with devastating effects on the credit market and eventually on the real economy ${ }^{19}$. Increases in poverty were correspondingly smaller in Brazil than in Indonesia, Thailand or, for that matter, Argentina. Nevertheless, real incomes fell across the entire distribution, and aggregated poverty measures rose accordingly. The headcount index rose from $28.1 \%$ to $29.2 \%$. Since income falls were largest for the richest households, inequality fell for most commonly used measures. The Gini coefficient fell from 0.593 to 0.587 .

The main effect on the distribution of occupations was a substantial increase in unemployment levels across the board, but predominantly in urban areas, and for more skilled workers. In urban areas, the informal sector registered small increases in employment $(+3.5 \%)$, whereas the formal sector retrenched by $0.5 \%-1 \%$, regardless of skill level or the tradable nature of the goods. In rural areas, the picture is mixed. There was a pronounced move from employment in the informal and formal non-tradable sectors, toward the formal tradable sector (the sector that benefited from the real devaluation). The actual effects

19 The real GDP growth rate in Brazil in 1997, 1998 and 1999 was respectively $3.27 \% 1.32 \%$ and $0.81 \%-$ still in positive territory - as opposed to the dramatic changes from positive $6-8 \%$ real growth down to $-5 \%$ to $-15 \%$ in the same period in East Asian crisis-hit countries such as Thailand and Indonesia. 
on the distribution of earnings were also reasonably muted, at least in urban areas. Real wages fell for most groups, but rose substantially for workers in the rural non-tradable sector. Household incomes fell across the distribution, but less so for the poor than for the rich. The changes were thus generally equalizing, in the sense that skilled workers had greater declines than those with fewer years of schooling.

The predictive performance of the macro-micro model was uneven. Comparing occupational and earnings predictions from the macro-model alone with the observed changes (aggregated from the observed 1999 PNAD for the same household groups) yielded at best a mixed picture. As we saw in Section 3, the model made a number of mistakes even in the direction of employment changes, and the magnitude of the errors was generally large. The performance for the earnings LAVs was better, but not stellar. In this case, at least, there were no errors of direction, and only about one-third of predictions were off by 5 percentage points or more.

When the macro and micro modules were combined, however, so that the linkage aggregate variable predictions were not uniformly attributed to households in the corresponding groups, but instead allocated in ways that respected the correlations present in the household data, performance improved quite substantively. In Section 5, we saw that errors in occupational predictions were smaller for the macromicro model than they had been for the macro model alone. The same pattern held for earnings. Indeed, looking at the distribution of incomes in a truly disaggregated manner, as we did in Section 6, reveals a rather less damning verdict on the macro-micro modeling exercise. While the integrated model failed to replicate the incidence of changes in incomes along the distribution perfectly, it did get both the direction and the basic pattern of incidence right. In fact, its prediction errors were statistically indistinguishable from the sampling errors inherent in comparing two separate PNAD samples (1998 and 1999). Importantly, the integrated model performed much better than the simple representative household groups approach would have, even under the assumption that the latter would get all the macro changes exactly right.

All in all, we definitely do not claim that this approach has delivered the ability to predict the distributional outcomes of macroeconomic shocks or policy packages with anything near perfect accuracy. We also recognize that both the macro and the micro modeling are data and computation intensive, and that large macro-econometric models are not the most elegant tools in the professional toolkit. Nevertheless, we do find evidence that the integrated approach delivers a capacity to predict the distributional impacts of a macroeconomic shock in a manner that is both broadly acceptable and considerably superior to existing alternative approaches, such as the representative household groups approach. 
The crucial element in this improvement over RHG approaches seems to be the use of the microeconomic simulations, so as to allocate broad average changes (in wages or occupations within groups) in ways that are consistent with the various heterogeneities that matter at the individual level, within each one of those large groups. If the experience of the 1999 devaluation in Brazil is anything to go by, policymakers interested in anticipating the distributional impacts of macroeconomic shocks or policies could do worse than to experiment with integrated models of this kind.

\section{References}

Adelman and Robinson, S. (1988), Macroeconomic Adjustment and Income Distribution: Alternative Models Applied to Two Economies, Journal of Development Economics, 29(1), 23-44.

Artus P., Deleau M. and Malgrange P.(1986), Modélisation Macroéconomique, Economica, 1986.

Baldacci, Mello and Inchauste (2002) "Financial Crises, Poverty, and Income Distribution", IMF Working Paper Series 0204

Bourguignon, F., Ferreira, F.H.G. and Lustig, N. (1998) 'The Microeconomics of Income Distribution Dynamics in East Asia and Latin America' (mimeo), World Bank, DECRA: Washington DC.

Bourguignon, F., Robilliard, A.-S. and Robinson, S. (2002): "Crisis and Income Distribution: A Macromicro Model for Indonesia", mimeo, IFPRI, Washington, DC, April 2002

Cardoso E. (2002), "Implicit and Explicit Taxation of Financial Interdiaries in Brazil: The Effect of Reserve Requirements on Bank Spreads", mimeo

Elbers, C., Lanjouw, J.O., Lanjouw, P. and Leite, P.G. (2001): "Poverty and Inequality in Brazil: New Estimates from Combined PPV-PNAD Data", World Bank, DECRG Mimeo.

Fallon P. and Lucas B. (2002) "The Impact of Financial Crises on Labor Markets, Household Incomes, and Poverty: A Review of Evidence", World Bank Research Observer ( web site) v 17 (1)21-45.

Favero C.and Giavazzi F. (2002) “Why are Brazil's Interest Rates So High" Bocconi University - IGIER and IGIER (Bocconi University) SSRN Electronic Paper Collection

Fernandes, R. and Menzes-Filho, N. (2001) "Escolaridade e Demanda Relativa por Trabalho : Uma Avaliação para o Brasil nas Décadas de 80 e 90" , mimeo.

Ferreira, F. H.G., Lanjouw, P. and Neri, M. (2003): "A Robust Poverty Profile for Brazil using Multiple Data Sources", Revista Brasileira de Economia, 57 (1): 59-92.

Ferreira, F.H.G. and Barros, R. (1999) 'The Slippery Slope: Explaining the Increase in Extreme Poverty in Urban Brazil; 1976-96', Revista de Econometria, 19 (2): 211-96.

Fischer, F., Kein, L. and Shinkai, Y. (1965) "Price and Output Agrregation in the Brookings Econometric Model" The Brookings Quarterly Econometric Model of the US, Duesenberry, L. (ed.). Brookings Institution, 653-679. 
Lokshin M. and Ravallion M. (2000), "Welfare Impacts of the 1998 Financial Crisis in Russia and the Response of the Public Safety Net", The Economics of Transition, V 8 (2) 2000, pp.269-295.

Kakwani, N. (1998) "Impact of Economic Crisis on Employment, Unemployment and Real Income", National Economic and Social Development Board.

Pereira da Silva L. (2001), Boom and Bust in East-Asia: How the East-Asia Miracle produced the Financial Bubbles that ended in the 1997-98 Crises, mimeo, The World Bank, 2001.

Pereira da Silva L., Picchetti, P. and Samy de Castro A. (2004), "A macroeconometric financial model for Brazil estimated with the PNAD", mimeo, The World Bank, 2004.

Stern N., (1989), The Economics of Development: A Survey, Economic Journal v99, n397 (September 1989): 597-685

Townsend, Robert M., and Kenichi Ueda. 2001 "Transitional Growth with Increasing Inequality and Financial Deepening." IMF Working Paper WP/01/108, International Monetary Fund, Research Department, Washington, D.C. Processed. 
Annex 1

Main Equations of the Micro-Simulation Model

Log earnings regression

\begin{tabular}{|c|c|c|c|c|c|c|c|c|c|c|}
\hline & \multicolumn{6}{|c|}{ Urban - Formal Tradable } & \multicolumn{4}{|c|}{ Rural - Formal Tradable } \\
\hline & \multicolumn{2}{|c|}{ Low } & \multicolumn{2}{|c|}{ Intermediate } & \multicolumn{2}{|c|}{ High } & \multicolumn{2}{|c|}{ Low } & \multicolumn{2}{|c|}{ Inter + High } \\
\hline & Coef & P-value & Coef & P-value & Coef & P-value & Coef & P-value & Coef & P-value \\
\hline $\mathrm{R}^{2}$ & 0.27 & & 0.40 & & 0.36 & & 0.22 & & 0.42 & \\
\hline \#obs & 4,449 & & 9,004 & & 1,378 & & 1,910 & & 967 & \\
\hline Education & 0.069 & 0.01 & -0.051 & 0.06 & -0.505 & 0.09 & 0.195 & 0.00 & 0.033 & 0.40 \\
\hline Education2 & 0.008 & 0.14 & 0.011 & 0.00 & 0.024 & 0.02 & -0.021 & 0.01 & 0.006 & 0.00 \\
\hline Experience & 0.037 & 0.00 & 0.059 & 0.00 & 0.079 & 0.00 & 0.021 & 0.00 & 0.040 & 0.00 \\
\hline Experience2 & 0.000 & 0.00 & -0.001 & 0.00 & -0.001 & 0.00 & 0.000 & 0.07 & 0.000 & 0.03 \\
\hline Race - white & 0.189 & 0.00 & 0.168 & 0.00 & 0.380 & 0.00 & 0.186 & 0.00 & 0.198 & 0.00 \\
\hline NO & -0.064 & 0.13 & -0.124 & 0.00 & -0.038 & 0.76 & 0.123 & 0.25 & -0.062 & 0.67 \\
\hline NE & -0.326 & 0.00 & -0.348 & 0.00 & -0.099 & 0.10 & -0.197 & 0.00 & -0.153 & 0.01 \\
\hline SU & -0.073 & 0.00 & -0.075 & 0.00 & -0.060 & 0.21 & 0.045 & 0.26 & 0.037 & 0.46 \\
\hline $\mathrm{CO}$ & 0.066 & 0.05 & -0.085 & 0.00 & 0.205 & 0.01 & 0.199 & 0.00 & 0.215 & 0.00 \\
\hline Metropolitan area & 0.134 & 0.00 & 0.087 & 0.00 & 0.235 & 0.00 & 0.093 & 0.06 & 0.119 & 0.01 \\
\hline Gender: Male & 0.407 & 0.00 & 0.389 & 0.00 & 0.370 & 0.00 & 0.280 & 0.00 & 0.392 & 0.00 \\
\hline \multirow[t]{2}{*}{ Intercept } & 4.322 & 0.00 & 4.534 & 0.00 & 7.872 & 0.00 & 4.381 & 0.00 & 4.142 & 0.00 \\
\hline & \multicolumn{6}{|c|}{ Urban - Formal Non Tradable } & \multicolumn{4}{|c|}{ Rural - Formal Non Tradable } \\
\hline $\mathrm{R}^{2}$ & 0.24 & & 0.35 & & 0.38 & & 0.29 & & 0.47 & \\
\hline \#obs & 7,557 & & 17,959 & & 4,866 & & 803 & & 897 & \\
\hline Education & 0.018 & 0.31 & -0.065 & 0.00 & -0.101 & 0.50 & 0.094 & 0.03 & -0.046 & 0.27 \\
\hline Education2 & 0.008 & 0.06 & 0.012 & 0.00 & 0.010 & 0.05 & -0.014 & 0.17 & 0.010 & 0.00 \\
\hline Experience & 0.033 & 0.00 & 0.054 & 0.00 & 0.067 & 0.00 & 0.015 & 0.01 & 0.045 & 0.00 \\
\hline Experience2 & 0.000 & 0.00 & -0.001 & 0.00 & -0.001 & 0.00 & 0.000 & 0.15 & -0.001 & 0.00 \\
\hline Race - white & 0.148 & 0.00 & 0.195 & 0.00 & 0.283 & 0.00 & 0.085 & 0.02 & 0.301 & 0.00 \\
\hline NO & -0.098 & 0.00 & -0.082 & 0.00 & 0.017 & 0.76 & 0.175 & 0.12 & 0.087 & 0.58 \\
\hline NE & -0.287 & 0.00 & -0.297 & 0.00 & -0.217 & 0.00 & -0.238 & 0.00 & -0.144 & 0.01 \\
\hline SU & 0.014 & 0.44 & 0.010 & 0.42 & -0.038 & 0.18 & 0.098 & 0.03 & 0.003 & 0.96 \\
\hline $\mathrm{CO}$ & 0.055 & 0.02 & 0.040 & 0.01 & 0.107 & 0.00 & 0.121 & 0.04 & 0.209 & 0.00 \\
\hline Metropolitan area & 0.117 & 0.00 & 0.102 & 0.00 & 0.285 & 0.00 & 0.131 & 0.00 & 0.255 & 0.00 \\
\hline Gender: Male & 0.490 & 0.00 & 0.417 & 0.00 & 0.469 & 0.00 & 0.456 & 0.00 & 0.434 & 0.00 \\
\hline \multirow[t]{2}{*}{ Intercept } & 4.492 & 0.00 & 4.518 & 0.00 & 4.936 & 0.00 & 4.612 & 0.00 & 4.274 & 0.00 \\
\hline & \multicolumn{6}{|c|}{ Urban - Informal } & \multicolumn{4}{|c|}{ Rural - Informal } \\
\hline $\mathrm{R}^{2}$ & 0.29 & & 0.36 & & 0.35 & & 0.25 & & 0.33 & \\
\hline \#obs & 22,630 & & 24,459 & & 3,353 & & 11,136 & & 2,740 & \\
\hline Education & 0.037 & 0.00 & -0.049 & 0.02 & -0.692 & 0.00 & 0.072 & 0.00 & -0.044 & 0.16 \\
\hline Education2 & 0.013 & 0.00 & 0.010 & 0.00 & 0.033 & 0.00 & 0.006 & 0.17 & 0.010 & 0.00 \\
\hline Experience & 0.054 & 0.00 & 0.067 & 0.00 & 0.066 & 0.00 & 0.032 & 0.00 & 0.048 & 0.00 \\
\hline Experience2 & -0.001 & 0.00 & -0.001 & 0.00 & -0.001 & 0.00 & 0.000 & 0.00 & -0.001 & 0.00 \\
\hline Race - white & 0.142 & 0.00 & 0.179 & 0.00 & 0.182 & 0.00 & 0.143 & 0.00 & 0.140 & 0.00 \\
\hline NO & -0.169 & 0.00 & -0.142 & 0.00 & -0.137 & 0.04 & -0.158 & 0.00 & 0.061 & 0.46 \\
\hline NE & -0.439 & 0.00 & -0.391 & 0.00 & -0.277 & 0.00 & -0.375 & 0.00 & -0.354 & 0.00 \\
\hline SU & -0.122 & 0.00 & -0.030 & 0.03 & -0.078 & 0.04 & -0.024 & 0.33 & -0.089 & 0.03 \\
\hline co & -0.037 & 0.04 & -0.007 & 0.66 & 0.239 & 0.00 & 0.153 & 0.00 & 0.100 & 0.02 \\
\hline Metropolitan area & 0.223 & 0.00 & 0.133 & 0.00 & 0.238 & 0.00 & 0.290 & 0.00 & 0.272 & 0.00 \\
\hline Gender: Male & 0.646 & 0.00 & 0.608 & 0.00 & 0.489 & 0.00 & 0.578 & 0.00 & 0.503 & 0.00 \\
\hline Intercept & 3.736 & 0.00 & 4.090 & 0.00 & 8.598 & 0.00 & 3.726 & 0.00 & 4.050 & 0.00 \\
\hline
\end{tabular}

Source: PNAD/IBGE 1998 and author's calculation 
Occupational Structure Multinomial Logit Model: Marginal Effects

\begin{tabular}{|c|c|c|c|c|c|}
\hline \multirow[b]{2}{*}{ Heads } & \multicolumn{5}{|c|}{ Rural } \\
\hline & Inactive & Unemployed & Formal tradable & Formal non tradable & Informal \\
\hline Probability & 0.05 & 0.01 & 0.13 & 0.04 & 0.77 \\
\hline Gender - Male & -0.12 & -0.01 & 0.11 & -0.02 & 0.04 \\
\hline Education & 0.00 & 0.00 & 0.01 & 0.01 & -0.02 \\
\hline Education2 & 0.00 & 0.00 & 0.00 & 0.00 & 0.00 \\
\hline Experience & 0.00 & 0.00 & 0.00 & 0.00 & 0.00 \\
\hline Experience2 & 0.00 & 0.00 & 0.00 & 0.00 & 0.00 \\
\hline Race - white & 0.00 & 0.00 & 0.01 & 0.00 & -0.01 \\
\hline Status of house ocupation (tenant or owner) & 0.01 & 0.00 & -0.11 & 0.00 & 0.10 \\
\hline Other incomes & 0.00 & 0.00 & 0.00 & 0.00 & 0.00 \\
\hline \#0a9 & 0.00 & 0.00 & 0.01 & 0.00 & -0.01 \\
\hline \#10a18 & 0.00 & 0.00 & 0.02 & -0.01 & -0.02 \\
\hline \#19a64 & -0.01 & 0.00 & 0.00 & 0.00 & 0.01 \\
\hline$\# 65 e^{+}$ & 0.00 & 0.00 & 0.00 & 0.00 & 0.01 \\
\hline NO & -0.03 & 0.00 & -0.07 & -0.01 & 0.11 \\
\hline NE & -0.02 & -0.01 & -0.11 & -0.03 & 0.16 \\
\hline SU & -0.02 & 0.00 & -0.04 & -0.02 & 0.08 \\
\hline $\mathrm{CO}$ & -0.04 & -0.01 & -0.03 & -0.03 & 0.10 \\
\hline Metropolitan area & 0.05 & 0.01 & 0.03 & 0.06 & -0.14 \\
\hline \multicolumn{6}{|l|}{ Spouse } \\
\hline Probability & 0.67 & 0.02 & 0.01 & 0.04 & 0.26 \\
\hline Gender - Male & -0.42 & 0.01 & 0.03 & 0.08 & 0.30 \\
\hline Education & -0.01 & 0.00 & 0.00 & 0.01 & 0.00 \\
\hline Education2 & 0.00 & 0.00 & 0.00 & 0.00 & 0.00 \\
\hline Experience & -0.03 & 0.00 & 0.00 & 0.00 & 0.02 \\
\hline Experience2 & 0.00 & 0.00 & 0.00 & 0.00 & 0.00 \\
\hline Head's education & 0.00 & 0.00 & 0.00 & 0.00 & 0.00 \\
\hline Head's experience & 0.00 & 0.00 & 0.00 & 0.00 & 0.00 \\
\hline Dummy if head is Formal Tradable & 0.05 & 0.00 & 0.02 & 0.01 & -0.08 \\
\hline Dummy if head is Formal non Tradable & -0.05 & 0.00 & 0.01 & 0.03 & 0.01 \\
\hline Head's race & 0.00 & 0.00 & 0.00 & 0.00 & 0.00 \\
\hline Race - white & 0.03 & -0.01 & 0.00 & 0.00 & -0.03 \\
\hline Status of house ocupation (tenant or owner) & 0.01 & 0.01 & 0.00 & 0.00 & -0.01 \\
\hline Other incomes & 0.00 & 0.00 & 0.00 & 0.00 & 0.00 \\
\hline \#0a9 & 0.00 & 0.00 & 0.00 & 0.00 & 0.00 \\
\hline \#10a18 & 0.01 & -0.01 & 0.00 & 0.01 & -0.02 \\
\hline \#19a64 & -0.03 & 0.00 & 0.00 & 0.00 & 0.03 \\
\hline$\# 65 e^{+}$ & 0.02 & 0.00 & 0.00 & -0.01 & 0.00 \\
\hline NO & -0.06 & -0.01 & -0.03 & -0.02 & 0.12 \\
\hline NE & -0.06 & -0.02 & -0.01 & 0.00 & 0.09 \\
\hline SU & -0.12 & 0.00 & 0.01 & 0.01 & 0.10 \\
\hline $\mathrm{CO}$ & -0.05 & -0.01 & 0.00 & -0.01 & 0.06 \\
\hline Metropolitan area & 0.03 & 0.01 & 0.00 & 0.02 & -0.06 \\
\hline \multicolumn{6}{|l|}{ Others } \\
\hline Probability & 0.43 & 0.06 & 0.04 & 0.03 & 0.45 \\
\hline Gender - Male & -0.47 & 0.00 & 0.06 & 0.00 & 0.41 \\
\hline Education & -0.03 & 0.01 & 0.00 & 0.01 & 0.01 \\
\hline Education2 & 0.00 & 0.00 & 0.00 & 0.00 & 0.00 \\
\hline Experience & -0.04 & 0.00 & 0.00 & 0.01 & 0.03 \\
\hline Experience2 & 0.00 & 0.00 & 0.00 & 0.00 & 0.00 \\
\hline Head's education & 0.02 & 0.00 & 0.00 & 0.00 & -0.02 \\
\hline Head's experience & 0.00 & 0.00 & 0.00 & 0.00 & 0.00 \\
\hline Dummy if head is Formal Tradable & 0.05 & 0.01 & 0.05 & 0.00 & -0.11 \\
\hline Dummy if head is Formal non Tradable & 0.02 & 0.02 & 0.00 & 0.02 & -0.06 \\
\hline Head's race & 0.00 & 0.00 & 0.00 & 0.00 & 0.00 \\
\hline Race - white & 0.03 & -0.01 & 0.00 & 0.01 & -0.03 \\
\hline Status of house ocupation (tenant or owner) & 0.04 & -0.01 & -0.02 & -0.01 & -0.01 \\
\hline Other incomes & 0.00 & 0.00 & 0.00 & 0.00 & 0.00 \\
\hline \#0a9 & 0.00 & 0.00 & 0.00 & 0.00 & -0.01 \\
\hline \#10a18 & 0.02 & -0.01 & 0.00 & -0.01 & 0.00 \\
\hline \#19a64 & -0.01 & 0.00 & 0.00 & 0.00 & 0.02 \\
\hline$\# 65 e^{+}$ & -0.02 & 0.00 & 0.00 & 0.00 & 0.02 \\
\hline NO & 0.08 & -0.04 & -0.04 & -0.01 & 0.01 \\
\hline NE & 0.07 & -0.02 & -0.04 & -0.01 & 0.00 \\
\hline SU & -0.08 & -0.02 & 0.02 & 0.00 & 0.08 \\
\hline $\mathrm{CO}$ & 0.00 & -0.02 & -0.01 & -0.01 & 0.05 \\
\hline Metropolitan area & 0.13 & 0.04 & 0.01 & 0.03 & -0.21 \\
\hline
\end{tabular}


Occupational Structure Multinomial Logit Model: Marginal Effects

\begin{tabular}{|c|c|c|c|c|c|}
\hline \multirow[b]{2}{*}{ Heads } & \multicolumn{5}{|c|}{ Urban } \\
\hline & Inactive & Unemployed & Formal tradable & Formal non tradable & Informal \\
\hline Probability & 0.15 & 0.04 & 0.13 & 0.22 & 0.47 \\
\hline Gender - Male & -0.22 & -0.02 & 0.15 & 0.02 & 0.08 \\
\hline Education & 0.01 & 0.00 & 0.01 & 0.00 & -0.02 \\
\hline Education2 & 0.00 & 0.00 & 0.00 & 0.00 & 0.00 \\
\hline Experience & 0.01 & 0.00 & 0.00 & 0.00 & 0.00 \\
\hline Experience2 & 0.00 & 0.00 & 0.00 & 0.00 & 0.00 \\
\hline Race - white & 0.01 & -0.01 & 0.00 & 0.00 & -0.01 \\
\hline Status of house ocupation (tenant or owner) & 0.01 & -0.01 & 0.01 & 0.00 & -0.01 \\
\hline Other incomes & 0.00 & 0.00 & 0.00 & 0.00 & 0.00 \\
\hline \#0a9 & 0.01 & 0.01 & 0.00 & 0.01 & -0.02 \\
\hline \#10a18 & 0.03 & 0.01 & 0.00 & -0.01 & -0.02 \\
\hline \#19a64 & -0.02 & 0.00 & 0.01 & 0.00 & 0.01 \\
\hline$\# 65 e^{+}$ & -0.01 & 0.00 & 0.00 & -0.01 & 0.02 \\
\hline NO & -0.03 & -0.01 & -0.09 & -0.06 & 0.18 \\
\hline NE & -0.01 & -0.01 & -0.07 & -0.04 & 0.12 \\
\hline SU & -0.04 & 0.00 & 0.01 & 0.01 & 0.02 \\
\hline $\mathrm{CO}$ & -0.03 & 0.00 & -0.07 & 0.02 & 0.08 \\
\hline Metropolitan area & 0.01 & 0.02 & 0.00 & 0.05 & -0.07 \\
\hline \multicolumn{6}{|l|}{ Spouse } \\
\hline Probability & 0.60 & 0.05 & 0.02 & 0.10 & 0.23 \\
\hline Gender - Male & -0.50 & 0.04 & 0.06 & 0.14 & 0.26 \\
\hline Education & 0.01 & 0.00 & 0.00 & 0.00 & -0.01 \\
\hline Education2 & 0.00 & 0.00 & 0.00 & 0.00 & 0.00 \\
\hline Experience & -0.02 & 0.00 & 0.00 & 0.00 & 0.01 \\
\hline Experience2 & 0.00 & 0.00 & 0.00 & 0.00 & 0.00 \\
\hline Head's education & 0.01 & 0.00 & 0.00 & 0.00 & -0.01 \\
\hline Head's experience & 0.00 & 0.00 & 0.00 & 0.00 & 0.00 \\
\hline Dummy if head is Formal Tradable & 0.05 & 0.00 & 0.02 & 0.00 & -0.08 \\
\hline Dummy if head is Formal non Tradable & 0.00 & 0.00 & 0.00 & 0.05 & -0.05 \\
\hline Head's race & 0.00 & 0.00 & 0.00 & 0.00 & 0.00 \\
\hline Race - white & 0.05 & -0.01 & 0.00 & -0.01 & -0.03 \\
\hline Status of house ocupation (tenant or owner) & 0.01 & -0.01 & 0.00 & 0.00 & 0.00 \\
\hline Other incomes & 0.00 & 0.00 & 0.00 & 0.00 & 0.00 \\
\hline \#0a9 & 0.00 & 0.00 & 0.00 & 0.01 & -0.01 \\
\hline \#10a18 & 0.05 & 0.00 & 0.00 & -0.02 & -0.03 \\
\hline \#19a64 & -0.02 & 0.00 & 0.00 & 0.00 & 0.01 \\
\hline$\# 65 \mathrm{e}^{+}$ & 0.05 & 0.00 & -0.01 & -0.03 & -0.02 \\
\hline NO & 0.02 & -0.01 & -0.01 & -0.03 & 0.04 \\
\hline NE & 0.02 & -0.01 & -0.01 & -0.02 & 0.03 \\
\hline SU & -0.08 & 0.01 & 0.01 & 0.03 & 0.03 \\
\hline $\mathrm{CO}$ & -0.01 & 0.00 & -0.02 & 0.00 & 0.03 \\
\hline Metropolitan area & -0.01 & 0.02 & 0.01 & 0.01 & -0.02 \\
\hline \multicolumn{6}{|l|}{ Others } \\
\hline Probability & 0.41 & 0.13 & 0.05 & 0.13 & 0.28 \\
\hline Gender - Male & -0.21 & 0.01 & 0.05 & 0.02 & 0.14 \\
\hline Education & -0.04 & 0.01 & 0.01 & 0.02 & 0.00 \\
\hline Education2 & 0.00 & 0.00 & 0.00 & 0.00 & 0.00 \\
\hline Experience & -0.05 & 0.00 & 0.01 & 0.02 & 0.02 \\
\hline Experience2 & 0.00 & 0.00 & 0.00 & 0.00 & 0.00 \\
\hline Head's education & 0.03 & 0.00 & 0.00 & -0.01 & -0.02 \\
\hline Head's experience & 0.00 & 0.00 & 0.00 & 0.00 & 0.00 \\
\hline Dummy if head is Formal Tradable & 0.01 & 0.00 & 0.04 & 0.00 & -0.05 \\
\hline Dummy if head is Formal non Tradable & -0.01 & 0.00 & 0.00 & 0.04 & -0.04 \\
\hline Head's race & 0.00 & 0.00 & 0.00 & 0.00 & 0.00 \\
\hline Race - white & 0.02 & -0.01 & 0.00 & 0.01 & -0.01 \\
\hline Status of house ocupation (tenant or owner) & -0.01 & 0.01 & 0.00 & 0.01 & -0.01 \\
\hline Other incomes & 0.00 & 0.00 & 0.00 & 0.00 & 0.00 \\
\hline \#0a9 & -0.02 & 0.00 & 0.01 & 0.01 & 0.00 \\
\hline \#10a18 & 0.02 & 0.00 & 0.00 & -0.01 & -0.01 \\
\hline \#19a64 & 0.01 & 0.00 & -0.01 & -0.01 & 0.01 \\
\hline$\# 65 \mathrm{e}^{+}$ & 0.00 & 0.00 & 0.00 & -0.01 & 0.01 \\
\hline NO & 0.11 & -0.02 & -0.06 & -0.08 & 0.04 \\
\hline NE & 0.12 & -0.02 & -0.06 & -0.07 & 0.02 \\
\hline SU & -0.02 & -0.01 & 0.01 & 0.01 & 0.01 \\
\hline $\mathrm{CO}$ & -0.01 & -0.01 & -0.04 & 0.00 & 0.05 \\
\hline Metropolitan area & 0.01 & 0.04 & -0.01 & 0.02 & -0.06 \\
\hline
\end{tabular}

